\title{
LA JUNTA DE ACREEDORES: UNA VISIÓN COMPARADA*
}

\author{
RAÚl NÚŃEZ OJEDA* \\ ARTEMIO Aguilar MARTÍNEZ ${ }^{* * *}$
}

RESUMEN: La presente investigación trata esencialmente acerca de las formas de participación que tienen los acreedores dentro de la quiebra. Esta ha tenido diversos vaivenes a lo largo de la historia, los que han dado lugar a diferentes sistemas que intentan incesantemente darles cabida en un procedimiento cada vez más técnico y comprensivo de los más variados intereses. Daremos a conocer las formas en que importantes sistemas jurídicos comparados han recogido esta participación, como también la situación del ordenamiento chileno frente a ellos y su relación con un procedimiento que exige, cada día más, una mayor celeridad y eficiencia. Por último aplicaremos las categorías comparadas al modelo chileno, realizando un análisis funcional y orgánico del sistema, procurando extraer críticas y soluciones al debilitado sistema concursal nacional.

PALABRAS CLAVE: Derecho Comercial - Derecho de Quiebras - Junta de Acreedores - Comité de Acreedores - Poderes.

\section{THE CREDITORS' MEETING: A COMPARATIVE VIEW}

ABSTRACT: This research is essentially about the ways of participation by creditors in the bankruptcy. Throughout history, it has had many ups and downs, which have taken place into different systems, constantly trying to accommodate them in a growing technical and logical procedure of a wide range of interests. We will release the important ways in which compared legal systems have collected this participation, as well

* Este trabajo se enmarca dentro del proyecto FONDECYT regular $\mathrm{N}^{\circ} 1100530$ titulado "Hacia una nueva Justicia Concursal", cuyo investigador principal es el profesor Dr. Raúl Núńez Ojeda de la Pontificia Universidad Católica de Valparaíso.

Fecha de recepción: 3 de febrero de 2012.

Fecha de aceptación: 11 de octubre de 2012.

** Licenciado en Ciencias Jurídicas por la Universidad de Valparaíso (Chile); Doctor en Derecho por la Universidad Pompeu Fabra (España); Profesor Asociado de Derecho Procesal en la Pontificia Universidad Católica de Valparaíso (Chile). Correo electrónico: raul.nunez@ ucv.cl.

*** Egresado en Derecho por la Universidad Católica de Valparaíso; Ayudante de Derecho Procesal en la Facultad de Derecho de la Universidad Católica de Valparaíso. Correo electrónico: a.aguimar@hotmail.com. 
as the situation of the Chilean system towards them and the relationship with a procedure that requires increasingly, greater speed and efficiency. Finally, it will be applied the compared categories to the Chilean model, using a functional and organic system, trying to extract reviews and solutions of the weak national system.

KEY WORDS: Commercial Law - Bankruptcy Law - Meeting of Creditors - Creditors Committee - Powers.

\section{1) INTRODUCCIÓN}

Cuando un deudor se encuentra en estado de insolvencia, confluyen diversos actores e intereses con miras a superarla. En ese sentido, distintos sistemas concursales han hecho hincapié en las diversas relaciones jurídicas existentes entre deudores y acreedores concurrentes, elaborando procedimientos que intentan tomar en cuenta todos los elementos, tanto procesales como sustantivos ${ }^{1}$, que se desenvuelven en este particular tipo de ejecución. De esa forma, la junta de acreedores se constituye como un órgano vital dentro de dichos procedimientos, siendo una de las tantas instituciones que nos permiten afrontar el conflicto desde el punto de vista del interés privado, asumiendo como tarea primordial la de manifestar la voluntad de los sujetos activos envueltos en el proceso. Así, como consecuencia de la declaración de quiebra, se origina la formación de la llamada "masa de acreedores" 2 la cual corresponde a una unión virtual entre los acreedores del concurso, que permite que la mayoría de ellos pueda imponer su criterio a la minoría según los parámetros y formas establecidos en la ley ${ }^{3}$, y cuyo fin es lograr la realización más conveniente de la masa de la quiebra y el pago ajustado a derecho de sus respectivas acreencias ${ }^{4}$.

La quiebra como institución y, por supuesto, la junta de acreedores se encuentran reguladas en Chile por la ley No 18.175 , publicada en el Diario Oficial el día 28 de octubre del año 1982. Posteriormente han habido diversas reformas al sistema, las cuales también han repercutido

1 Calvocaravaca, Alfonso Luis y Carrascosa González, Javier: Derecho concursal internacional, Colex, Madrid, 2004, p. 14.

2 BÖHM, Bastian: "Die Gläubiger - Gläubigergruppen, Gläubigerorganisation, Gläubigerversammlung", en Handbuch des Insolvenzrechts, Editado por Karl WolfhartNitsch, Ed. EHV, Bremen, 2011, p. 135.

3 Sandoval LÓPEZ, Ricardo: Derecho Comercial, La insolvencia de la empresa. Derecho Concursal: Quiebras, convenios y cesiones de bienes, Sexta ed, Ed. Jurídica, Santiago, 2007, p. 163.

4 Baeza Ovalle, José Gonzalo: Derecho concursal: procedimiento de liquidación de bienes. La Quiebra, V. III, Punto Lex, Santiago, 2011, p. 717. 
en las facultades de las juntas de acreedores (V. gr. ley No 20.004 del año 2005). Sin embargo, tanto en lo que respecta a la justicia concursal en general, como a las juntas en particular, no existe una reforma que reestructure significativamente nuestro ordenamiento, por lo que la situación actual no difiere tanto de lo establecido bajo la vigencia de la antigua ley de quiebras.

Más allá de la dictación de leyes, como la aludida No 20.004 o No 20.073 del año 2005, que en palabras de la Superintendencia de Quiebras $^{5}$ han hecho del sistema una solución más eficaz, accesible y transparente, hoy en día se intenta dar un paso mucho más grande en la idea de realizar reformas más que cosméticas al sistema, llevando a la ejecución universal por la senda que se ha propuesto la reforma procesal civil respecto de la ejecución individual. De esa manera, la Superintendencia del ramo no ha querido quedar exenta de estos aires reformistas y ha entablado una política de estudios que arriben a propuestas legislativas para modificar nuestro Derecho Concursal; derecho que adolece de fuertes contradicciones, dado que encuentra su origen en un añejo sistema poco ajustado a la realidad jurídica y económica del país. Así, una economía moderna como la chilena, no puede estar sujeta a un sistema concursal anacrónico e ineficiente como el actual ${ }^{6}$.

Por otro lado, más allá de nuestras latitudes, la doctrina europea ha constatado la existencia de una crisis en los diferentes sistemas concursales ${ }^{7}$, que en épocas de descalabros económicos como los actuales, derivan en la preocupación urgente de modificaciones acordes a la realidad de cada país, lo que en buena parte, sirve de fundamento para el siguiente trabajo y el proyecto en el que este está envuelto.

En este contexto, vemos cómo la participación de los acreedores en la insolvencia resulta tremendamente importante a la hora de planificar un sistema concursal. En virtud de sus facultades y características, la junta que los reúne ha constituido, para la doctrina nacional, un órgano totalmente necesario en el procedimiento de insolvencia, naciendo no de la voluntad de sus integrantes, sino por requerimiento de la ley, la que consagra los requisitos y formas para su constitución. Con una estructura colegiada y facultades que abordan (y desbordan) el procedimiento, los acreedores reunidos en junta se han convertido en los directores de las quiebras, aunque, tal como veremos, dicha dirección dista mucho de ser la de un rector preocupado y diligente.

NúŃEz OJeda, Raúl, Estudio sobre Justicia Concursal para la Superintendencia de Quiebras, Cuarto Informe, Superintendencia de Quiebras, Santiago de Chile, 2009, p. 9.

SANDoval López: (n. 6), p. 164.

A propósito del sistema español, Vid, Vacas Medina, Luis: "Críticas a los procesos concursales vigentes", Ponencia presentada en las "Jornadas de Derecho Procesal", enero, Madrid, 1984 (en línea). En www.mjusticia.gob.es [consulta: 10 de julio de 2012]. 
El gran número de poderes otorgados al órgano en cuestión, y que se encuentran diseminados a lo largo de toda nuestra legislación, nos dan a entender la importancia que ha significado su instauración en nuestro sistema, como también su relación directa con el futuro del procedimiento de quiebra. De ese modo, la tarea de esta investigación será analizar la realidad comparada respecto a los poderes otorgados a las juntas de acreedores, o a los órganos o instancias que los representan, de modo de verificar cómo es tratada dicha participación y, en definitiva, determinar si el sistema chileno puede acomodarse o no a las distintas alternativas que nos otorga la doctrina y la legislación ajenas a nuestra fronteras.

De esa forma veremos que, en el derecho comparado, prácticamente todos los procesos de ejecución contemplan órganos auxiliares del tribunal para un mejor desarrollo del proceso, pero comparativamente no tienen identidad de funciones ni de atribuciones ${ }^{8}$. Así, las estructuras acentuadamente publicistas prescinden en buena medida de la voluntad de los acreedores y del deudor; en contraste con las legislaciones más inclinadas hacia una predominancia privatística, donde los acreedores y el deudor asumen un papel más protagónico ${ }^{9}$. Con ello, daremos paso a un cotejo de la normativa extranjera, donde analizaremos distintas tendencias que apuntan su mirada a diversas formas de participación de los acreedores, avanzando en una intervención ordenada por parte del Estado, de modo de hacer realidad los objetivos de la quiebra en un tiempo acorde a la situación suspensiva de los derechos de sus acreedores, de sus trabajadores, y de la realidad socioeconómica que rodea a una empresa en insolvencia.

\section{2) ANTECEDENTES HISTÓRICOS}

Muchas veces cuando queremos aludir y estudiar los antecedentes históricos de alguna institución jurídica, recurrimos al Derecho Romano ${ }^{10}$, como cuna de todos los grandes sistemas normativos que hoy conocemos. $\mathrm{Y}$ es que, resulta tentador aludir a la rica cultura clásica cuando tratamos temas de esta índole, sin embargo, hoy en día la doctrina está conteste en que no es allá donde surgen los procedimientos de quiebra tal como los conocemos hoy, sino que ello lo encontramos recién en las escuelas estatutarias del bajo medioevo ${ }^{11}$. En el Derecho Romano no exis-

\footnotetext{
8 Puga Vial, Juan: Derecho Concursal. El juicio de Quiebras, T. II, Tercera ed., Ed. Jurídica, Santiago, 2009, p. 555.

$9 \quad$ Ibíd.

10 Para un panorama general acerca de la quiebra en el Derecho Romano, Vid. Desurvire, Daniel: “La Quiebra a través de los tiempos", en Revista de Derecho, Universidad de Concepción, V. LXIV, No199, 1996, pp. 61 y ss.

11 Román Rodríguez, Juan Pablo: Instituciones de Derecho Concursal, Abeledo Perrot, Santiago, 2011, pp. 4-5.
} 
tían instituciones que tengan relación con la quiebra y los procedimientos concursales en general, sino que existían instituciones que más bien correspondían a formas de coacción sobre la voluntad del deudor reacio ${ }^{12}$.

No obstante ello, haremos una breve alusión a los embargos en el Derecho Romano (missio in bona o missiones in possessionem), pues no podríamos pasar por alto algunas características que, si bien no corresponden en toda su plenitud a un procedimiento de quiebra, sí nos dan antecedentes acerca de la participación de los acreedores en el sistema clásico $^{13}$.

Así, una de las particularidades de la missio in bona era la de ser una ejecución patrimonial (ajena a las ejecuciones personales tan conocidas con anterioridad a lalexpoeteliapapilia), que consistía en la venta del patrimonio del deudor con la finalidad de satisfacer a los acreedores, teniendo en cuenta desde ya, la conformación de diversos tipos de créditos privilegiados y valistas. Es este el caso que parte de la doctrina ha puesto como ejemplo de un rasgo distintivo de la quiebra en el Derecho Romano pues, según dicen, esto correspondía a una verdadera ejecución patrimonial concursal, dándose a favor de todos los acreedores involucrados ${ }^{14}$. Lo importante de ello, era que el procedimiento se vinculaba con una marcada visión privatista de la ejecución (llamado incluso de autodefensa), siendo dirigido por los mismos acreedores, a quienes, con la puesta en posesión de bienes, se les atribuía un derecho patrimonial: el de promover la venta y repartirse el precio ${ }^{15}$.

La concepción privatista romana se va diluyendo en el tiempo frente a la consolidación del Derecho Estatutario, el cual se conoce por ser el que, con mayor precisión, abordó la labor de estudiar doctrinal y jurisprudencialmente las instituciones concursales ${ }^{16}$. Así, las legislaciones estatutarias del siglo XIII nos presentan una variada gama de instancias tendientes a obtener el cumplimiento por mediación del mismo obligado o la venta de sus bienes, sobre los que el fallido debía dar juramento y dar en depósito a una autoridad de carácter público ${ }^{17}$. En este caso, estamos ante un procedimiento marcado por una concepción jurídico-pública de la quiebra, caracterizado por su gran rigurosidad, en donde se parte de la

\footnotetext{
12 Provinciali, Renzo: Tratado de Derecho de Quiebra, T. III, Barcelona, 1959, p. 93.

13 Vid. Arriagada, Juan Pablo: "Pervivencia de Principios e Instituciones romanas en la Quiebra chilena", Memoria para optar al grado de licenciado en ciencias jurídicas, Santiago, 1996. Betancourt, Fernando: "El concurso de acreedores en el derecho romano clásico", en Estudios sobre la Ley concursal:libro homenaje a Manuel Olivencia, Marcial Pons, Madrid, 2005, p. 112.

15 Garrigues, Joaquín: Curso de Derecho Mercantil, T. V., Temis, Bogotá, Colombia, 1987, p. 11.

16 Fonster, Wolfgang: KonkursalsVerfahren: Francisco Salgado de Somoza in der Geschichte des Insolvenzrechts, Ed. Böhlau, Köln, 2008, p. 375.

17 Provinciali: (n. 15), p. 100.
} 
idea de que el deudor es un verdadero defraudador, incumbiéndole al Estado la represión del hecho ilícito de la quiebra, como finalidad a la que va unida la satisfacción de los acreedores ${ }^{18}$.

De ese modo, estamos ante procedimientos cuya tramitación, en gran parte, se da de oficio, procediendo el magistrado a incautar los bienes del deudor y distribuyéndolos por su cuenta a los acreedores ${ }^{19}$. Sin embargo, a medida que se vio reforzada la autoridad estatal, la ejecución privada fue perdiendo aún más fuerza, dando paso a una ejecución del patrimonio del deudor como monopolio exclusivo del Estado.

En tal contexto, encontramos en las normas estatutarias muchas de las características que vemos hoy en día en variadas legislaciones concursales. En lo que respecta a este trabajo, podemos percatarnos de una regulación bastante precisa acerca de los órganos de la quiebra, existiendo actores de carácter judicial y otros de corte administrativo. Los primeros eran encargados de dar el impulso inicial al procedimiento y dirigir el mismo, mientras que los segundos se caracterizaban por ser verdaderos auxiliares de los tribunales, teniendo facultades que variaban según la legislación de que se trate ${ }^{20}$.

Aquí es donde encontramos el origen de la participación de los acreedores mediante asambleas (assembleadeicreditori), aunque también ya se reconocía la posibilidad de estructurarlos mediante órganos específicos de representación (capi deicreditori); en uno y otro caso, poco a poco se fueron otorgando a los mismos más atribuciones en el desarrollo del procedimiento. En el primer caso (asambleas), la regla general indica que su principal función era la de aprobar o rechazar los convenios, para lo cual se adoptaba el principio de las dobles mayorías, en donde se exigía un grado de participación numérica y representativa. En segundo lugar, los capi deicreditori representaban el origen de lo que hoy conocemos como comités de acreedores, en los que se constituye un órgano de representación, donde participan alrededor de tres acreedores que personifican la voluntad de toda la colectividad. Estos órganos partieron simplemente como una forma de manifestar la voluntad del conjunto de los acreedores, aunque con posterioridad se les otorgaron facultades más importantes, como las de realizar transacciones y pagos, como también la de decidir sobre el futuro de los convenios ${ }^{21}$.

Prosiguiendo con este análisis, hemos de recordar la gran influencia que tuvieron estas legislaciones en el Código de Napoleón de 1807 (a

\footnotetext{
18 Garrigues: (n. 18), p. 11.

19 Ibíd.

20 En todo caso, la regla general iba por la línea de otorgarles potestades relacionadas a la administración y ejecución del patrimonio del deudor. Âlvarez SAN José, María: El poder de decisión de los acreedores en el concurso, Ed. Civitas, Madrid, 2005, p. 85. 
través de la Ordennance), el cual si bien reconoce amplias facultades a los acreedores, opta por una solución burocratizada de las crisis concursales, con fuertes controles públicos ${ }^{22}$. Incluso, la doctrina criticó, en su oportunidad, el escaso poder asignado a los acreedores en el concurso, los cuales se sometían a la omnipotencia del síndico, quien fue ganando poder debido, precisamente, a la desidia de los primeros, quienes carecían de iniciativa y valor para representar los intereses que les eran propios ${ }^{23}$. En el caso del derecho español, la influencia no es tan reconocida por la doctrina, la cual alude a una visión publicista del sistema, donde la intervención de la autoridad era constante en todo el proceso, limitando el poder de los acreedores. Por ello, si bien se reconoció la constante intervención del juez como característica distintiva del procedimiento, debe considerarse, sin embargo, que la abundancia de competencias judiciales no supuso forzosamente la negación de la autonomía de los acreedores, ya que determinados trámites de ese juicio se encomendaban enteramente a los mismos, vinculando la decisión de estos al propio juez ${ }^{24}$.

Con ello, llegamos a otra normativa clásica dentro del sistema comparado histórico: las Ordenanzas de Bilbao de 1737. Este apartado traerá enorme importancia para nuestro estudio, pues dichas normas estuvieron vigentes durante mucho tiempo en nuestro país (1795-1867), las que solo se vieron modificadas sustancialmente con la entrada en vigencia del Código de Comercio. Además, y tal como nos comenta Soza, nuestro derecho actual de quiebras encuentra sus bases en la legislación hispana; concretamente en las Siete Partidas (Alfonso X, 1256-1265), las Ordenanzas de Bilbao (Felipe V, 1737) y la Novísima Recopilación (1805)25.

En las Ordenanzas la quiebra estaba desarrollada en el capítulo XVII, el cual se tituló "De los atrasos y quiebras". En él se configuran 56 leyes, las que contienen un sistema cuyos principios no tienen nada que envidiar a los actuales ejes de las legislaciones concursales ${ }^{26}$. En esta normativa, las juntas de acreedores cumplían un rol fundamental, por lo que no es de extrańar que su regulación haya sido bastante rigurosa. De ese modo, este órgano concursal era concebido como un "procedimiento destinado a tratar materias de interés común y tomar acuerdos colectivos" 27 .

22 Pulgar Ezquerra, Juana: La Declaración del Concurso de Acreedores, Ed. La Ley, Madrid, 2005, p. 82.

23 Laborderie, Pierre: "La Masa de acreedores y el control de la quiebra", en Revista de Derecho y Jurisprudencia y Gaceta de Tribunales, V. 1, No 15, 1918, p. 175.

24 Álvarez San José: (n. 23), p. 99.

25 SozaRied, María de los Ángeles: "El procedimiento concursal del derecho romano clásico y algunas de sus repercusiones en el actual derecho de quiebras", en Revista de estudios histórico-jurídicos, Valparaíso, No 20, 1998, p. 6.

26 Arriagada: (n. 16), p. 42.

27 Carrasco, Jorge: Evolución del Derecho de Quiebras en Chile, Ed. Jurídica, Santiago, 1963, p. 49. 
El sistema era estructurado en base a una primera junta, la que debía convocarse por el Prior y los Cónsules interinos, quienes manifestaban lo obrado respecto de su actuación en el procedimiento. Posteriormente se procedía a una segunda junta, donde comparecían todos los acreedores notificados en la primera, y en la cual podían votar determinados acuerdos, tales como, (i) la comparecencia personal del fallido para que solucione las deudas que existían en la confección de la memoria general encomendada a los síndicos comisarios, (ii) resolver materias en el caso de que se proponga un convenio y (iii) acordar todas las providencias conducentes a la quiebra ${ }^{28}$.

De ese modo, llegamos al Código de Comercio francés de 1807, otra gran fuente de inspiración de la legislación concursal nacional, que introdujo por primera vez el sistema de asamblea de acreedores dentro del derecho galo. Durante su vigencia, eran los jueces los encargados de convocar a los acreedores, aunque también podía hacerlo, en ciertas circunstancias, el comisario. Lo que se destaca de esta regulación era la celeridad que los franceses quisieron imponer a su sistema concursal, estableciendo plazos perentorios para su perfeccionamiento (V. gr. la lista de acreedores tenía que estar conformada en los tres días siguientes a la disposición del balances, la verificación de los créditos solo podía realizarse dentro de 15 días, etc.).

Este texto, de enorme influencia en el derecho español y europeo, otorga a los acreedores la posibilidad de participar como grupo en el procedimiento, lo que se manifiesta en dos materias fundamentales: por un lado, en el nombramiento de los que serán sus representantes, y por el otro, la decisión sobre las propuestas de convenio ${ }^{29}$.

En cuanto al ámbito nacional, recordemos que son las Ordenanzas de Bilbao las que mayor influencia han ejercido sobre nuestro sistema. Así, vale volver sobre su extensa aplicación, la cual se extendió por 72 ańos. Por ello, no resulta extraño que durante su larga vida haya sufrido modificaciones provenientes de leyes y códigos nacionales, entre las cuales destacanla (i) ley de juicio ejecutivo de 1837, (ii) la ley de prelación de créditos de 1845 y (iii) la ley de prelación de créditos de $1854^{30}$.

Entre ellas, lejos la de mayor trascendencia es la primera, la que constituye una de las llamadas Leyes Marianas, y que ha sido fuente de diversas normas acerca de juicio ejecutivo en nuestro país, siendo reproducida, casi literalmente, por el Código de Comercio. De esa forma la citada ley, en su Art. 150, derogó todas las leyes anteriores relativas al juicio ejecutivo, concurso de acreedores y cesión de bienes, en todo aquello que

Ibíd, p. 50.

Álvarez San José: (n. 23), p. 104.

Arriagada: (n. 16), p. 51. 
fuere contrario a su texto ${ }^{31}$. La ley, en su Título II, trató acerca de la posición de terceros en el juicio ejecutivo y concurso de acreedores, colocando al concurso como agregado al juicio ejecutivo. Por otro lado, en su Título III reguló las cesiones de bienes y el convenio entre deudor y acreedores, estableciendo además las condiciones para nombrar al síndico, sus deberes y causales de remoción, como también lo relativo a las juntas de acreedores y a la proposiciones de convenio ${ }^{32}$. No obstante ello, las leyes de 1837 y 1845 aún tenían diversos vacíos, por lo que eran insuficientes para proteger los intereses de los acreedores del fallido y del comercio en general $^{33}$, por lo que forzosamente se llegó al Código de Comercio, el cual otorgó un papel preponderante a las juntas de acreedores, en busca de poder subsanar los defectos que, históricamente, habían presentado las legislaciones concursales.

En conclusión, la evolución histórica de la participación de los acreedores reunidos en junta ha tenido variadas e intensas modificaciones. Cada una de ellas recuerda las críticas de su regulación anterior, por lo que no resulta extraño que la normativa comparada tome esta característica e intente por diversos modos sistematizar el poder de decisión de los acreedores.

\section{3) VISIÓN COMPARADA ACERCA DE LA PARTICIPACIÓN DE LOS ACREE- DORES}

Con el valioso aporte que nos brinda el derecho comparado podemos percatarnos de la forma en que las diversas legislaciones concursales han tomado en cuenta los antecedentes históricos recién mencionados, y cómo han ido perfeccionándolos dentro de su propia realidad jurídicoeconómica ${ }^{34}$. De ese modo, analizaremos las formas empleadas por estos sistemas, tanto desde una perspectiva orgánica, donde veremos diversos modelos de intervención de los acreedores y, por otro lado, desde una visión funcional, en la que analizaremos si el derecho comparado ha adoptado una visión de los acreedores como dueños del procedimiento de quiebra, o simplemente como meros partícipes del mismo.

\footnotetext{
$31 \quad$ Ibíd.

32 Salas González, Manuel: "De las Quiebras: (comentarios sobre algunas disposiciones sustantivas del titulo IV de la ley 4.558)", Memoria de prueba para optar al grado de licenciado en ciencias jurídicas, Santiago, 1940, p. 8.

33 Ibíd.

34 Para un panorama general acerca de la realidad comparada europea respecto de la Insolvencia, Vid, Pannen, Klaus: EuropeanInsolvencyRegulation: Commentary, Ed. De Gruyter, Berlin, 2007, passim.
} 


\section{1.) DERECHO COMPARADO: UNA VISIÓN ORGÁNICA}

En cuanto a las formas de organizar la participación de los acreedores, en derecho comparado hemos de reconocer la existencia de diversos modelos. En este tema resultan fundamentales las opciones de política legislativa acerca de los intereses afectados por la insolvencia de un deudor $^{35}$. Por un lado, la visión que toma en consideración a los acreedores como únicos afectados por la quiebra postula un modelo de intervención público-judicial mínima, donde solo se proporcionan elementos para ordenar la participación de los mismos. Por otro lado, los ordenamientos que consideran otros intereses en su tutela (deudor, trabajadores, comunidad, etc.), dando al procedimiento una fisonomía donde los poderes de los acreedores son mucho más restringidos. Por ello, los diversos sistemas concursales deben hacerse cargo de la forma en que participarán los órganos judiciales, los deudores y los acreedores, teniendo atención en que estos últimos pueden hacerlo desde la "expresión colegial de voluntades", o mediante juntas, comités de acreedores, o incluso la sola adición de voluntades individualmente expresadas ${ }^{36}$. Así, se reconocen dos grupos de sistemas: por un lado, aquel que establece como punto de partida la autonomía de la voluntad de los acreedores, al que se denomina (i) "modelo privado", y por otro, los que atribuyen a órganos públicos la administración del procedimiento, denominado (ii) "modelo judicial o público"37.

En primer lugar, el modelo privado se caracteriza por una actuación activa de los acreedores, a quienes se les otorga prácticamente una autotutela respecto de los bienes del fallido, basado principalmente en una visión que los enmarca como verdaderos (y únicos) interesados en el desarrollo y resultado del procedimiento. Sin embargo, es lógico entender que la referida "autotutela" no se da de una forma tan literal como pueda pensarse, pues la prohibición de autotutela exige que la jurisdicción, en el ámbito de la ejecución, cuente con los medios idóneos para lograr materialmente lo ordenado, adjudicando el deber al Estado de poner a disposición de los ciudadanos un sistema de ejecución que efectivamente logre la satisfacción del crédito y garantice la seguridad del tráfico ${ }^{38}$. Por lo tanto, dicha autotutela no significa que se excluya toda intervención del órgano judicial o de profesionales de la administración de insolvencias, sino que

Tirado, Ignacio: Los Administradores Concursales, Ed. Thomson Civitas, Navarra, 2005, p. 127.

ÁlVArez SAN JosÉ: (n. 23), p. 129.

Ibíd.

PéRez Ragone, Álvaro; Silva, Óscar: "Deber de transparencia patrimonial y efectividad de la ejecución: corolario del imperativo de cooperación procesal", en Cuadernos de Extensión Jurídica, U. de los Andes, No 16, 2009, p. 220. 
garantiza una participación ordenada y técnica en las etapas que competan a cada uno de los órganos de la quiebra.

Así, tenemos un modelo donde la situación de insolvencia del deudor puede y debe ser solucionada mediante negociaciones directas entre acreedores y el concursado, teniendo los primeros la atribución de decidir sobre el mejor modo de resolver las cuestiones que plantea la satisfacción de sus créditos, sin supeditar necesariamente dichas decisiones a órganos judiciales o administrativos. Por ello, la intervención de los órganos de naturaleza pública se reduce al mínimo, pues la facultad de tutela de poderes decisorios discrecionales que afecten a la administración o a la solución final de la crisis queda exclusivamente en manos de las partes ${ }^{39}$.

En ese sentido, se distingue entre dos submodelos básicos, dependiendo si la participación de los acreedores se canaliza a través de un órgano colegiado (en Chile la junta de acreedores), o si, por el contrario, se arbitra una forma de participación individual, con lo que llegamos a los submodelos orgánicos e inorgánicos respectivamente. En primer lugar, el submodelo orgánico nos expone a un conjunto de acreedores que constituyen una asamblea para que, de forma colectiva, discutan las posibles propuestas formuladas y proceder a la votación de las mismas ${ }^{40}$. Este sistema fue el adoptado, por ejemplo, en España (bajo la antigua legislación concursal otorgada por el Código de Comercio de 1829 y 1885) y actualmente en la legislación alemana (Insolvenzordnung, o InsO), donde estas asambleas pueden nombrar al administrador definitivo en determinados casos ( $\$ 13 \mathrm{Ins} \mathrm{O})$, al comité de acreedores ( $\$ 68 \mathrm{InsO})^{41}$ y pueden deliberar acerca de las enajenaciones del patrimonio especialmente importantes $(\$ 160 \mathrm{Ins} O)^{42}$. No obstante ello, el sistema alemán contempla mecanismos que sirven para no entrabar el procedimiento en caso de que las asambleas no se reúnan, el cual consiste en que los acreedores puedan emitir su voto por escrito con anterioridad a la celebración de la asamblea $(\$ 242 \mathrm{InsO})^{43}$.

Otro sistema representante de este modelo es el portugués, el cual tiene una singular importancia debido a la actualidad de su legislación, la que data del año 2004 con la dictación del Código de insolvencia y de recuperación de la empresa en falencia. Dicho Código está imbuido claramente por la protección al interés de los acreedores, otorgándoles amplias potestades dentro del procedimiento mediante el robustecimiento de la junta de acreedores y de una sesgada desjudicialización, la que conlleva

Tirado: (n. 38), p. 293.

Álvarez SAN JosÉ: (n. 23), p. 135.

ReIschl, Klaus: Insolvenzrecht, Ed. Müller, Heidelberg, 2008, p. 60.

Depré, Peter; Eickmann, Dieter, Flessner, Alex, VV.AA.: Insolvenzordnung. Heidelberg

Kommentar (Hrsg. Gerhard Kreft), CF. Müller, Heidelberg, p. 2008. 
a instituir un juez al que solo le corresponde declarar la insolvencia, sin siquiera poder pronunciarse sobre la posibilidad de la recuperación ${ }^{44}$. De esa forma, el protagonismo de los acreedores se manifiesta en la posibilidad de modificar a la persona del Administrador de la Insolvencia designado por el juez (Art. 53), cooperar y fiscalizar el ejercicio de las funciones del Administrador (Art. 55), solicitar cuentas al mismo (Art. 62), constituir o prescindir de la existencia de un comité de acreedores que los represente (Art. 67), otorgar alimentos al fallido (Art. 84), pronunciarse sobre el Informe de Liquidación (Art. 156), aprobar los planes de insolvencia (Arts. 209-212), entre otras.

En América Latina podemos apreciar ejemplos como el brasileño, donde la Ley de recuperación judicial y extrajudicial y quiebra del empresario y de la sociedad empresaria, del año 2005, instituye una asamblea general de acreedores bastante activa, lo que tiene su máxima exposición en la aprobación, rechazo o modificación del plan de recuperación que presenta el deudor (Art. 35.I, a) ${ }^{45}$. Además, se encarga de designar al comité de acreedores, eligiendo a sus miembros (Art. 26) quienes tienen, a su vez, importantes facultades, tanto en la quiebra (Art. 27.I) como en la recuperación judicial (Art. 27.II). Además de Brasil, tenemos el caso de Perú, donde la junta adopta la decisión sobre el destino del deudor (Art. 3, Ley General del Sistema Concursal), y el de Uruguay, donde tiene importantes facultades con respecto a la propuesta del plan del deudor (Art. 138, Ley concursal uruguaya).

En segundo lugar, se encuentra el submodelo inorgánico, llamado también sistema de adhesiones, al cual se adscriben el sistema concursal estadounidense y el italiano, donde no se prevé una asamblea o reunión de acreedores. Este subsistema decide ir más allá de lo que puede plantear uno donde es posible la votación por escrito fuera de la asamblea (lo que esencialmente diferencia ambos modelos), pues ni siquiera se prevé la existencia de asamblea alguna, de modo que todos los votos son emitidos por escrito. Así, se han planteado diferentes mecanismos para poner de acuerdo a los acreedores, como por ejemplo, la instauración de comités compuestos por algunos de ellos, y que tienen la misión de expresar lo decidido por los mismos, teniendo funciones de diversa naturaleza, tales como las de vigilancia, control, autorización y consulta respecto del curador (síndico) (como en el caso italiano, manifestado en el Art. 41 de su ley concursal, acerca de las Funzioni del comitato) ${ }^{46}$, o en el caso norteamericano, la de enviar a los correos electrónicos de los acreedores la información respectiva para que puedan remitir sus preferencias (Rule

\footnotetext{
44 Dasso, Ariel: Derecho Concursal Comparado, T. II, Legis, Buenos Aires, 2007, p. 1299.

45 Dasso, Ariel: Derecho Concursal Comparado, T. I, Legis, Buenos Aires, 2007, p. 231.

46 Lo Cascio, Giovanni: IlFallimento, Ed. Klüwer, Italia, 2007, pp. 267-272.
} 
3018, BankruptcyCode) ${ }^{47}$. De ese modo, se trata de respetar el interés de los acreedores en el concurso, pero, por razones de eficiencia, se opta por eliminar a las juntas como órganos esenciales dentro del procedimiento.

En el caso italiano, si bien existe un órgano, como lo es el comité, no existe una junta o comisión donde se deba expresar la visión de la totalidad de los acreedores. Es eso lo que los diferencia de los sistemas recién mencionados, en que existe un sistema dual de junta y comités, donde, por regla general, los segundos son instituidos y disueltos por los primeros, quienes finalmente deciden sobre el futuro de la quiebra. En este caso, existe solo el comité, el cual es designado por el juez dentro de los 30 días siguientes a la sentencia de quiebra, para lo cual es oído previamente el curador ${ }^{48}$. De esa forma, la doctrina entiende que el gobierno de la quiebra queda en manos de la mayoría de los acreedores titulares de la mayoría de los créditos, pues estos influyen en forma dirimente en la designación del curador y del mismo comité de acreedores ${ }^{49}$. Incluso, el sistema italiano, dirigiéndose más allá de lo que pueda plantear un sistema puramente orgánico, se desmarca de la participación de los acreedores desde un punto de vista absolutamente personal, y da lugar a la posibilidad de sustituir su intervención por un grupo de expertos (Art. 40).

En todo caso, estos modelos, tal como señalamos, no olvidan del todo la actuación de órganos públicos (como el juez), los cuales tienen una participación reservada dentro del proceso, la cual puede ser previa, posterior o concomitante.

Como no ha podido ser de otro modo, la decadencia del modelo orgánico es ya aceptada en derecho comparado. El ocaso de este sistema viene aparejado, sobre todo, por la inasistencia de los acreedores, por lo que los sistemas adscritos a este modelo han debido incorporar mecanismos que permitan la debida representación de los actores dentro del procedimiento, de modo de no configurar un retraso en el mismo ${ }^{50}$. Además, no es posible desconocer que el sistema de juntas eleva sustancialmente los costes del procedimiento, los que pueden ser de índole puramente económicos, temporales o de gestión, derivados de las propias características del órgano que, naturalmente, es colegiado. Por lo demás, los acreedores no basan sus decisiones exclusivamente en un análisis coste-beneficio, sino que toman en consideración otras variables que, en muchas ocasiones, solo tienen un contenido económico secundario o reflejo, lo que se agrava al tener en consideración que los integrantes de la masa pasiva forman

\footnotetext{
47 Newton, Grant: Bankruptcy and Insolvency Accounting, Practice and Procedure, $7^{\mathrm{a}}$ ed., Ed. John Wiley\&Sons, United States of America, 2009, p. 519.

48 DAsso: (n. 47), p. 947.

49 Ibíd.

50 Álvarez San José: (n. 23), p. 140.
} 
una unidad de decisión cerrada e impuesta imperativamente, lo que significará la mayor satisfacción de unos en detrimento de otros ${ }^{51}$.

Así, en el otro lado, nos encontramos con los modelos judiciales o "públicos" (también llamado de "heterotutela pública"), el cual se define por la sustracción a los acreedores de la decisión sobre cuál debiera ser el modo de satisfacción de sus créditos y, en definitiva, de solución de la crisis concursal del deudor. El paradigma en este caso, lo representa el derecho francés, en el cual se eleva a un fin fundamental, no al interés único de los acreedores, sino a un interés ajeno que tiene que ver directamente con la supervivencia de la empresa. La desconfianza en la capacidad de los acreedores concursales, como sujeto decisorio, conlleva no solo a una reducción en sus competencias, sino que incluso a una disminución del propio número de los mismos, pues el sistema público se basa en una idea clara: los acreedores son sujetos parciales y representan, entre sí, intereses heterogéneos, por lo que su presencia debe quedar reducida a algo casi testimonial. El papel secundario de los acreedores, tiene como contrapartida natural la atribución de una gran cantidad de funciones al órgano jurisdiccional, pero con tal sobrecarga de deberes, se hace necesario crear una figura jurídica delegada de aquel que permita la continuidad en el seguimiento de cada concurso (V. gr : Administración concursal) ${ }^{52}$.

De esta forma, el derecho francés intenta coordinar todos los procedimientos de quiebra desde un punto de vista publicista, donde lo primordial, en primer lugar, es evitar la insolvencia, para luego, y en caso de que ello no sea posible, evitar la liquidación de la empresa. Por ello se establecen medios preventivos, como la conciliación y el salvataje, aunque sin desconocer el saneamiento y la propia liquidación cuando los mecanismos anteriores no hayan dado abasto.

En América Latina también existen ejemplos de sistemas donde lo público tiene mayor preeminencia en el desenvolvimiento de la quiebra. Así, un ejemplo es el caso argentino, donde el síndico es el verdadero eje del procedimiento concursal, estando sometido siempre a la dirección del juez del concurso (Art. 274, Ley de concursos y quiebras) ${ }^{53}$. Por ello, sus facultades se encuentran diseminadas a lo largo de toda la ley, comprendiendo prácticamente la totalidad del procedimiento, siendo las fundamentales, desde la recepción de los pedidos de reconocimiento de crédito que formulan los acreedores, emitir informes sobre las mismas, conservación de bienes, su liquidación y la distribución del remanente, hasta la conclusión del concurso. Otro caso similar es el expuesto por Colombia en que el síndico, denominado "Promotor", actúa como un verdadero

Tirado: (n. 38), p. 301.

Ibíd, p. 290.

Dasso: (n. 48), p. 152. 
auxiliar de justicia, eliminando su antigua carátula de "amigable componedor" que venía impresa en la antigua legislación ${ }^{54}$. Por último, tenemos el sistema mexicano, el cual instituye al IFECOM (Instituto Federal de Especialistas de Concursos Mercantiles) como un órgano auxiliar del Consejo de la Judicatura Federal encargado de supervigilar a los órganos de la quiebra, como también de llevar estadísticas de las mismas, lo que en cierto grado se asemeja a la Superintendencia de Quiebras chilena. Así, el síndico, bajo la supervigilancia del IFECOM, resalta entre los órganos con mayor poder de decisión dentro del procedimiento, relegando a los acreedores con poderes de carácter reactivo, donde pueden oponerse solo a ciertos acuerdos con las mayorías que establece la Ley de concursos mercantiles.

Sea que nos ubiquemos en sistemas públicos o privados, se ha intentado dar cabida a los acreedores reordenando su estructura, pero evitando el letargo del sistema de juntas. Así, se han creado los llamados comités de acreedores, los cuales nacen con la pretensión de evitar que todos los acreedores deban participar en cada una de las fases del procedimiento concursal, lo que constituye un importante incentivo para su participación en la quiebra ${ }^{55}$. Su naturaleza es la de ser un verdadero mandatario del conjunto de los acreedores, siendo un ejemplo de ellos el creditors' committee norteamericano, compuesto exclusivamente por acreedores elegidos entre titulares de créditos comunes, y cuya función es tutelar los intereses de los mismos, mediante facultades de control, pudiendo consultar al trustee sobre aspectos relativos a la administración de la quiebra. Dichas facultades se acrecientan si se trata de la reorganización de la empresa en cuestión, pues en tal caso pueden, incluso, proponer un convenio propio. Por otro lado, encontramos en la legislación alemana un comité (Gläubigerausschuß) conformado por representantes de pequeńos y mayores acreedores ordinarios, como también aquellos acreedores con derecho de satisfacción separada ( $\$ 67.2$ InsO). Sin embargo, la idea del comité, como dijimos, es representar el interés de acreedores, produciendo con ello que estos no tengan que manifestarse sucesivamente mediante juntas, lo que no se condice con la conformación otorgada al órgano por la legislación germana, en donde se configura a partir de diversos acreedores con intereses bastante diferentes, y cuyas funciones van, desde ser un órgano de vigilancia, hasta trabajar al lado del administrador del concurso ${ }^{56}$. En la ley concursal italiana también tenemos un ejemplo de esta institución, la que adquiere, con la nueva legislación, el reconocimiento que se le otorgaba

\footnotetext{
54 Ibíd., p. 413.

55 United Nations: Guía Legislativa sobre el Régimen de la Insolvencia, United Nations Publications, 2006, p. 239.

56 Acerca del Comité de acreedores alemán, Vid, Hess, Harald: Insolvenzrecht, Ed. Müller, Heidelberg, 2007, pp. 248-253.
} 
por el Código de Comercio del 82, vigilando la gestión del curador (Art. 41 LC), debiendo opinar acerca del plan económico (Art. 160.1 LC) y teniendo que autorizar al curador para la realización de actos de administración extraordinaria, asumiendo una tarea que antes le correspondía al juez (Art. 35) ${ }^{57}$. En nuestro país el único esbozo acerca de esta institución se da a propósito de la llamada "comisión de acreedores", la que puede constituirse para velar por el fiel cumplimiento del convenio, estando sujeta a las atribuciones y deberes que le indique la junta (Art. 206 inc. $3^{\circ}$ de la ley de quiebras), lo que, sin embargo, no ha tenido la relevancia práctica esperada ${ }^{58}$.

Para concluir con la visión orgánica es necesario hacer una breve reseña a uno de los países en donde se ha reformado con mayor fuerza su normativa: España ${ }^{59}$. La nueva legislación concursal, aparte de unificar los diversos procedimientos de insolvencia, unifica también los diversos órganos colaboradores del juez en la administración del concurso, instituyendo un órgano único a este respecto, cual es la "administración concursal" 60 . De ese modo, el actual sistema español define solo dos órganos necesarios: el juez instructor, dotado de amplias facultades discrecionales, y la mencionada Administración ${ }^{61}$.

57 Otros ordenamientos en donde se ha instaurado este órgano, han sido, por ejemplo, en Perú y Uruguay, donde las juntas aún tienen extensos poderes dentro del procedimiento, pero cuentan con la facultad de poder delegar sus funciones en un comité, integrado, en el primer caso, por cuatro miembros y presidido por el presidente de la junta (Art. 44, Ley General del Sistema Concursal de Perú), y en el segundo, por tres titulares y tres suplentes elegidos por voto de quienes representen la mayor proporción del pasivo quirografario (Arts. 130 y 131, Ley Concursal de Uruguay). También en Portugal, donde su constitución ha dejado de ser obligatoria, incluso pudiendo ser sustituida por la propia asamblea cuando el juez decida su instauración (Art. 66, Código da Insolvência e da Recuperaçâo de empresas). Argentina es otro ejemplo, donde el comité definitivo tiene una función de control del acuerdo preventivo y se conforma con acreedores que representen la mayoría del capital (Art. 45, Ley de Concursos y Quiebras), siendo además un ente contralor en la liquidación de la quiebra (Art. 201), con funciones de información y consejo (Art. 255 y 260). Por último, tenemos el caso brasileńo, donde la junta, además de tener facultades referidas al plan de recuperación que presenta el deudor (Art. 35. I, a, Ley de Recuperación judicial y extrajudicial y Quiebra del empresario y de las sociedad empresaria), designa al comité, compuesto por un representante de los acreedores laborales, otro a los privilegiados y otro quirografario (Art. 26). Vid. Dasso: (n. 47 y 48), passim. Para el caso argentino, Vid, Rivera, Julio; Roitman, Horacio; Vítolo, Daniel: Ley de Concursos y Quiebras, T. III, Ed, Rubinzal-Culzoni, Buenos Aires, 2000, p. 201.

Cifuentes Corona, Pablo: Los convenios judiciales, estudio de las alternativas a la quiebra, Copygraph, Santiago, 2009, p. 171.

Para una visión general acerca de la nueva ley concursal española, Vid. Vázquez Sotelo, José Luis: "La Nueva ley concursal espańola”, en Revista Iberoamericana de Derecho Procesal, V. IV, No 6, 2004; Rojo, Ángel; Beltrán, Emilio: Comentario de la ley concursal, T. I y II, Ed. Civitas, Madrid, 2004.

60 Pacheco Guevara, Andrés: La administración concursal, Aranzadi, Navarra, 2009, p. 36.

61 Ramos Torre, Javier: "La Administración concursal", en Cuadernos de Derecho judicial, No 18, 2003, p. 334 . 
En el caso ibérico, la administración concursal ha venido a desempeñar muchas de las funciones que, antaño, eran de propiedad de los acreedores. Con ello se pretende satisfacer la necesidad de hacer más eficiente el procedimiento concursal, mediante una reforma que, en entre otras cosas, trae una nueva y novedosa orgánica ${ }^{62}$. Así, los órganos necesarios de la quiebra lo constituyen, por un lado el juez especializado -lo que permite confiar en mayor medida en su criterio ${ }^{63}$-, y por otro, la administración ${ }^{64}$, la que se profesionaliza y actúa dentro de todas las etapas relevantes en el proceso, tanto en las de carácter jurídico como las económicas ${ }^{65}$. Tan importante ha resultado la labor de este órgano que se lo califica como los ojos del juez en el concurso, en donde la "posición jurídica de la administración se encuentra determinada, fundamentalmente, por cuatro ámbitos: el tipo de vinculación con el deudor cuyo patrimonio administra e interviene; el modo de adopción de decisiones y, sobre todo, los criterios que sigue el órgano al decidir; la relación frente a los terceros con los que entre en contacto jurídico al desarrollar la actividad concursal, y, en cuarto lugar, el reparto competencial interórganico realizado por el legislador al diseñar el concurso" 6 .

Esta tecnificación orgánica ha hecho que la doctrina española discuta reiteradamente sobre su adscripción a uno u otro modelo. Mientras algunos señalan que se ha pasado a un sistema público, otros aún ven en él reflejos de un modelo privatístico de autogestión por parte de los acreedores ${ }^{67}$. No obstante ello, la reforma española no solo vino a modificar la orgánica concursal, sino que también trajo consigo un verdadero desapoderamiento de las facultades de los acreedores reunidos en junta, lo que redunda en tener una balanza más cercana a la visión publicista que a la de "autotutela".

62 Petit Lavall, María Victoria: "La Junta de Acreedores", en Estudios sobre la Ley concursal: libro homenaje a Manuel Olivencia, Marcial Pons, Madrid, 2005, p. 1473.

63 Para un análisis acerca de las competencias funcionales del juez del concurso español, Vid, Sánchez-Calero Guilarte, Juan; Adrián Arnaiz, Antonio Javier: Comentarios a la legislación concursal, V. I, Ed. Lex Nova, Valladolid, 2004, pp. 238 y ss.

64 Este órgano ha evolucionado de diversas formas desde su incorporación en el año 2003. Vid. YANES YANES, Pedro: "La reforma inacabada de la administración concursal en el real decreto-ley 3/2009, de 27 de marzo", en Revista de derecho concursal y paraconcursal: anales de doctrina, praxis, jurisprudencia y legislación, No 11, 2009; Barrio Calle, María Asunción: La Administración Concursal (en línea). En: www.cej-mjusticia.es, [consulta: 1 de octubre de 2011]; Gómez Martín, Fernando: "La Administración Concursal", en Estudios de Deusto, V. 2, No 50, 2002, pp. 49 y ss.

65 NúNez OJeda: (n. 8), p. 159.

66 Pacheco Guevara: (n. 63), p. 97.

67 Álvarez San José: (n. 23), p. 153. 


\section{2.) DERECHO COMPARAdO: UNA VISIÓN FUnCIONAL}

En este segundo apartado veremos la regulación comparada acerca de las facultades otorgadas a los acreedores, los que, como vimos, pueden agruparse de diversas formas. Hemos dicho también que, por regla general, los modelos privados otorgan a los acreedores diversas facultades para su desenvolvimiento en el proceso, las cuales se acentúan en el caso del submodelo orgánico, ocurriendo algo diverso en los modelos públicos, donde son despojados de muchas facultades en pos de fortalecer órganos de carácter judicial o administrativo.

Así, desde el punto de vista funcional, la tendencia comparada es clara al despojar a los acreedores de muchos de los poderes que, otrora, eran de competencia de los mismos, sea que estén reunidos en junta o no. Dicha circunstancia es tomada como una verdadera política legislativa basada, principalmente, en las dificultades de reunir y poner de acuerdo a un grupo de personas tan diversas como distantes. Y es que los acreedores pueden atravesar circunstancias de toda índole que pueden embarazar su participación dentro del procedimiento. Dicho embarazo, propio de los sistemas de juntas, y más aún en las que gozan de enormes poderes, produce -como ya adelantamos- costes de diversa magnitud ${ }^{68}$ :

i) Por un lado, el factor económico generado por los gastos de convocatoria y celebración de las juntas, indispensables dentro del procedimiento, los que se elevan al otorgar más poderes a los acreedores;

ii) La dilación del procedimiento es otro factor a considerar, el cual se acrecienta en los sistemas de doble mayoría como el chileno. De ese modo, el sistema de juntas se vuelve reiterativo, dilatorio y costoso, sobre todo cuando vemos que ciertos acuerdos pueden ser impugnados por otros acreedores, lo cual finalmente tendría que decidirse en otro estadio, haciendo perder una gran cantidad de tiempo en la tramitación de la quiebra;

iii) En cuanto a la gestión del sistema de juntas, la posibilidad de convocar y poner de acuerdo a todos, o a la gran mayoría de los acreedores, se ve enfrascada en sucesivos llamados que no son respondidos en la forma en que el legislador espera; $y$

iv) La información disímil, y a veces distorsionada, que tienen los acreedores reunidos en junta, al no poder participar de igual manera en el procedimiento, provoca que muchos de los acuerdos celebrados sean perfeccionados por mera intuición, y no por una real convicción basada en un conocimiento acabado sobre realidad de la insolvencia. 
Por otro, existen diversos obstáculos para la participación perfecta de los acreedores. En primer lugar, tenemos los intereses heterogéneos delos que son dueños los diversos acreedores, los cuales son muchas veces inconciliables ${ }^{69}$. En segundo lugar, un obstáculo de suma relevancia es la pasividad de los acreedores quienes, al no estar debidamente coordinados, generalmente hacen del sistema de juntas uno donde prima solo el que mayor interés tiene, es decir, el acreedor con créditos económicamente importantes dentro del pasivo. Ello porque los acreedores de menor envergadura no se sienten interesados en un procedimiento que les hará recuperar poco y nada de su acreencia, lo que se replica en sistemas como el estadounidense o el italiano ${ }^{70}$. En tercer lugar, los acreedores sufren de una tremenda falta de competencia técnica, lo que puede desembocar en decisiones erróneas, las que en ocasiones reflejan indolencia, negligencia, ignorancia e incluso torpeza ${ }^{71}$.

Todo lo ya mencionado ha hecho que legislaciones comparadas vayan subsanando o abandonando el sistema clásico, donde los acreedores son directores y protagonistas del sistema concursal. En el primer caso, en el que aludimos al esfuerzo por subsanar los defectos de los sistemas de juntas, encontramos el caso uruguayo, donde los acreedores son protagonistas excluyentes del sistema. Sin embargo, el legislador al percatarse de su constante desinterés, inserta algunos estímulos de los cuales depende, en gran medida, la suerte del concurso. De ese modo, se regulan ciertas "presunciones relativas" para poder solicitar la apertura del concurso, las que dan lugar a un trámite abreviado en caso que el deudor se oponga, donde pueden decretarse medidas cautelares como el embargo preventivo de bienes y derechos del deudor o la intervención del negocio, las que constituyen obstrucciones importantes para la actividad del deudor. También, existe un estímulo con gran contenido patrimonial, el que se manifiesta en que el $50 \%$ de su crédito quirografario (hasta el límite máximo del 10\% del pasivo), queda transformado en privilegiado (Art. 110.3, Ley concursal uruguaya). Dichos estímulos, a su vez, se contraponen con las fuertes presiones legales a las que son sometidos los deudores (V. gr. La calificación del concurso como fortuito y consecuentemente, la liberación de las sanciones a las que en cambio se expone en el caso del concurso "necesario" o a instancia del acreedor), lo que no corresponde sino al ob-

\footnotetext{
69 Tirado: (n. 38), p. 301.

70 A propósito de este supuesto, en el sistema estadounidense se afirma que en la mayoría de los casos, los acreedores ni siquiera se molestan en presentar un simple formulario de verificación de créditos porque no hay activos para distribuir. Vid, Ferriell, Jeff; Janger, Edward: Understanding Bankruptcy, Segunda ed., Ed. LexisNexis, New York, 2007, p. 148. Ibíd.
} 
jetivo manifiesto de la legislación uruguaya, cual es la de satisfacer el interés de los acreedores ${ }^{72}$.

En segundo lugar, se ha intentado renunciar a dicho paradigma mediante diversos sistemas donde se abandona derechamente el rol protagónico de los acreedores. No han sido pocas las legislaciones que han optado por limitar las facultades de los acreedores ${ }^{73}$, siendo una de ellas la italiana, en donde la regulación del llamado concordato fallimentare supuso un progresivo límite a los poderes de los acreedores en el procedimiento, mutando hacia un nuevo proceso en el que la celeridad y la eficacia constituyen el objetivo primordial del sistema, instaurando a un curador como verdadero protagonista del concurso ${ }^{74}$. Con ello, se establece que la propuesta de concordato está sujeta a examen preventivo del juez, quien debe solicitar el parecer, no vinculante, del curador y del comité de acreedores. De esta forma, si el juez considera que la propuesta es admisible, ordena su comunicación a los acreedores para que estos puedan expresar su disconformidad en la secretaría del juzgado, no siendo siquiera necesario que los acreedores a favor emitan efectivamente su voto, en cuanto que el silencio tiene valor de aceptación de la propuesta. De ese modo, resulta evidente que la legislación italiana ha dejado reducida a la junta o asamblea de acreedores a un órgano simplemente consultivo ${ }^{75}$.

Otra legislación que ha preferido limitar estos poderes ha sido la alemana, la que opta por una vía especial: otorgar al juez diversas facultades para asegurar que la independencia de los acreedores no derive en exce$\operatorname{sos}^{76}$. Con ello, la asamblea no se acota solo a un sistema consultivo como el italiano, pues ejerce una función de auxiliar y vigilante del administrador de la insolvencia en su gestión empresarial, con facultades para tomar conocimiento de libros y documentos monetarios 77 , además de la posibilidad de requerir al administrador de la insolvencia la entrega de información específica e informes progresivos ( $\$ 79 \mathrm{Ins} \mathrm{O})$, determinar la manutención que recibirá el deudor y su familia ( $\$ 100 \mathrm{Ins} \mathrm{O})$, disponer de un

Esta tendencia la podemos confrontar con sistemas como el portugués, cuya legislación del año 2004 (Código da Insolvência e da Recuperaçâo de Empresas), se basa esencialmente en el interés de los acreedores, quienes desenvuelven su voluntad en todo el proceso. Así, se pretende una desjudicialización, pero no se hace cargo de establecer un órgano robusto que se encargue del desinterés de los acreedores, pues el "administrador de la insolvencia" solo es una sombra en torno al protagonismo dado a las asambleas. En todo caso, el futuro de esta legislación, apartada de lo que veremos a continuación, solo podrá se evaluada cuando su funcionamiento de paso a beneficios o costos imprevistos del sistema, siendo por ahora prematuro criticar por completo su establecimiento. Vid, Ibíd, p. 1303.

Ibíd, p. 943.

Álvarez SAN José: (n. 23), p. 139.

Para un acercamiento a la historia de la influencia de los acreedores en el concurso, Vid, Böнм: (n. 5), p. 132 y ss.

DASSO: (n. 48), p. 18. 
acuerdo distinto respecto del destino de los objetos de valor ( $\$ 149 \mathrm{InsO}$ ) o cerrar o continuar el giro de la empresa, como también diseñar un plan de insolvencia, determinando el objetivo del mismo $(\$ 159 \mathrm{InsO})^{78}$.

No obstante ello, en donde con mayor fuerza vemos esta tendencia es nuevamente en el derecho español, donde los acreedores han dejado de ser el centro de atención del procedimiento, dando paso a un nuevo sistema donde sus otrora facultades han sido distribuidas en entes especializados y mucho más técnicos (V. gr. administración concursal) ${ }^{79}$. La configuración de este órgano y el papel que desempeña han sufrido, tras la promulgación de la ley concursal, un cambio importante por diversas razones: porque ha variado la propia concepción del procedimiento, orientado antes por una finalidad liquidatoria y de satisfacción del interés privado de los acreedores, y ahora más hacia el salvamento o conservación de la empresa; y porque se ha profesionalizado y agilizado la tramitación del procedimiento concursal ${ }^{80}$. Con ello se persigue una notoria economía de tiempo y de gastos, respecto de los antiguos procedimientos concursales $^{81}$, pues era demostrativa la lentitud del procedimiento por culpa del sistema de juntas que había implantado la legislación española antes del año 2003, en la cual la participación de los acreedores reunidos en un órgano colegiado solo servía para ralentizar el desarrollo del concurso ${ }^{82}$. Ello explica que el sistema español haya optado por cambios profundos en la organización del procedimiento, los que han afectado intensamente, tanto a la función como al régimen jurídico de las juntas ${ }^{83}$, pasando de ser un órgano con amplia presencia en diversos y fundamentales momentos del concurso, a un órgano de competencia única y exclusiva, cuyas atribuciones tradicionales han pasado a otros órganos más ágiles y técni$\cos ^{84}$.

Por ello, el sistema ibérico vivió un verdadero desmantelamiento de las facultades de los acreedores reunidos en junta. Se despojó a los mismos de gran parte de sus atribuciones dándoles un carácter de órgano subordinado o de existencia condicionada, que, en todo caso, ya no es

GadeA, Enrique: Iniciación al estudio del derecho concursal, Ed. Dykinson, Madrid, 2005, p. 111.

80 Fernández Torres, Isabel: "La representación de los acreedores por la Administración Concursal: Una prohibición implícita", en Anuario de Derecho Concursal, No 10, 2007, p. 285.

81 Petit Lavall: (n. 65), p. 1474.

82 Ibíd, p. 1476.

83 Quijano González, Jesús: "La Junta de Acreedores en la nueva legislación concursal”, en Revista de derecho concursal y paraconcursal: Anales de doctrina, praxis, jurisprudencia y legislación, No 3, 2005, p. 66.

84 Quijano González, Jesús: "La junta de acreedores en el nuevo derecho concursal", en Estudios sobre la Ley concursal: libro homenaje a Manuel Olivencia, Marcial Pons, Madrid, 2005, p. 1529. 
necesario dentro del procedimiento ${ }^{85}$. De ese modo, del ámbito de competencias de la junta, han desaparecido atribuciones relacionadas con la designación de la administración concursal (equivalentes a las que antes tenían respecto de los síndicos) y atribuciones relacionadas con el reconocimiento y clasificación de los créditos, dejando lo primero en manos del juez y lo segundo a cargo de la administración concursal ${ }^{86}$. Con esta reducción funcional ${ }^{87}$ de la junta, solo queda conectar a las mismas, de forma exclusiva y excluyente, con los convenios ${ }^{88}$. Así, cuando dijimos que las juntas, hoy en día, constituyen para el derecho español un órgano no necesario o de existencia condicionada, precisamente lo decíamos porque no puede convocarse para otro asunto, ni cabe tampoco aprovechar la reunión para introducir otras cuestiones diferentes de aquellas que tengan una relación directa con la votación de un convenio, pues esta es la finalidad exclusiva o propia de la junta ${ }^{89}$. Sin embargo, debemos tener en cuenta que incluso puede ocurrir que, abierta la fase de convenio, no se llegue a celebrar la junta, porque no se presente propuesta de convenio, o porque no se mantenga una propuesta anticipada y no aprobada o, presentada alguna, no sea admitida a trámite. Es más, la emisión del voto en la junta ni siquiera es el único sistema para la formación de tal voluntad, pues la ley reconoce la posibilidad de que los acreedores, antes de la junta, adhieran a la propuesta de convenio sin tener que presentarse personalmente a dicha votación ${ }^{90}$.

Con esta reforma el sistema español ha dado un paso gigante hacia un verdadero vaciamiento de las funciones de los acreedores, lo que se fundamentó, como veíamos, en que la junta jamás ha sido el órgano adecuado para ciertas atribuciones que, aún en Chile, desempeñan. Es por ello que el ordenamiento ibérico reconduce a las juntas a su papel natural, cual es decidir las bases acerca de la propuesta de convenio ${ }^{91}$.

Por último, cabe mencionar que la ley concursal española recién data del año 2003, por lo que su examen práctico debiese proceder en algunos años más. Sin embargo, ya se han querido incorporar mecanismos para salvar algunas deficiencias que han tenido las juntas de acreedores, lo que resulta del todo interesante, pues aun reduciendo categóricamente sus facultades, el sistema de juntas todavía sigue siendo un foco de reformas, por lo que la doctrina ha abogado por introducir un sistema que permita

Ibíd, p. 1540.

Rojo; Beltrán: (n. 62), p. 2044.

Quijano GonzÁlez: (n. 87), p. 1540.

Recordemos que en estos casos los acreedores deben sesionar en juntas, sin embargo, en el caso de la propuesta anticipada solo deben formar mayorías por medio de adhesiones individuales a la propuesta (Art. 108.6), Vid. DAsso: (n. 48), p. 503.

FERnÁndeZ Torres: (n. 83), p. 288.

Rojo; Beltrán: (n. 62), p. 2045.

Quijano González: (n. 87), p. 1534. 
la votación electrónica de los acreedores (Proxycards), tal como ya se establece por la legislación alemana, en la que procede cuando se haya previsto la votación en junta separada de la discusión del plan de insolvencia $(\$ 242 \mathrm{InsO})^{92}$.

Sin duda que la evolución constante del derecho procesal, paralelamente a la del derecho mercantil, harán de la legislación española un foco de atención respecto de diversas reformas que puedan plantearse en nuestro país. Los "malos vientos" 93 que llegaron a España, respecto de las juntas de acreedores, nos demuestran que dicha problemática no es, ni ha sido, una dificultad aislada que viva nuestro derecho, por lo cual bien vale estudiar referencias tan importantes como el caso español, el cual ha sido, en gran parte, fundamento de nuestro actual y longevo sistema.

\section{4) Modelo Chileno}

Después de analizar el panorama otorgado por el derecho comparado, cabe preguntarnos en qué categoría se encuentra el sistema concursal chileno respecto de ello. Así, nuestra ley de quiebras se inserta claramente en el criticado sistema privado-orgánico. De ese modo, las críticas realizadas a propósito de dicho modelo, hacen eco también en la realidad concursal chilena mediante el análisis de dos vías interconectadas. Por un lado, la histórica implantación de un órgano que reúne a los acreedores dentro del procedimiento, el cual conforma un aparataje pesado y poco ágil en su actuar ${ }^{94}$. De esta forma los órganos colegiados tienen varias virtudes, pero entre sus deficiencias precisamente están las ya apuntadas acerca de la junta, pues resulta siempre complicado reunir y poner de acuerdo a personas con intereses y ambiciones distintas y distantes, lo que se agrava aún más si tenemos en consideración que en la quiebra concurren personas con créditos impagos, cuyo único fin es provocar, con la mayor celeridad posible, la solución de los mismos. Por otro lado, podemos analizar la problemática desde un punto de vista funcional pues, como hemos dicho, la gran cantidad de facultades de los acreedores hacen que el procedimiento constantemente se vea entrampado ante la pasividad de los mismos. Por ello, aún en el caso de considerar la permanencia de las juntas como órgano protagonista de la quiebra, deberíamos propender a un acotamiento de sus poderes, lo que no significa, a priori, dejar de lado por completo a los acreedores, sino velar porque las facultades

\footnotetext{
92 Hess, Harald: Insolvenzrecht: Großkommentar in dreiBänden, V. 1, Ed. Müller, Heidelberg, 2007, p. 1427.

93 Quijano González: (n. 87), p. 1535.

94 Sandoval López: (n. 6), p. 172.
} 
dentro del procedimiento sean distribuidas conforme al grado de técnica y competencia suficientes.

\section{1.) CARÁCTER FUNCIONAL. HACIA UNA MAYOR ESPECIALIZACIÓN}

Desde un punto de vista funcional, la legislación chilena se aleja de prácticamente todas las tendencias descritas en el capítulo anterior. En este sentido, nuestra legislación ha tenido diversos vaivenes en cuanto a las prerrogativas otorgadas a los acreedores dentro del procedimiento de quiebra. En primer lugar, el Código de Comercio de 1865 presentó una visión bastante privatista del rol de los acreedores dentro de la quiebra ${ }^{95}$. En segundo lugar, la ley No 4.558 estableció un sistema totalmente contrario al anterior, el cual es fruto de un examen práctico a las quiebras que históricamente se habían desenvuelto en nuestro país. Dicho análisis comprendió que la visión privatista no era la salida para provocar un sistema concursal efectivo, pues tal como vimos, las juntas de acreedores muchas veces embarazaban en demasía el procedimiento, haciendo que el engranaje de este se moviera según los caprichos de entes privados que nada tenían que ver con los intereses divergentes dentro de la quiebra, los cuales no solo emanan del poder de los acreedores, sino también de la sociedad toda ${ }^{96}$. Así, la visión publicista trae aparejada una cierta restricción de los poderes de las juntas, las cuales ceden ante la creación de un sistema de sindicatura de carácter público, a la que se encargó la tarea de llevar adelante el procedimiento cuando este se vea trabado. Dicho sistema se mantuvo vigente hasta la ley No 18.175 , la cual se instauró en base a las críticas que merecía la legislación antecesora, sobre todo respecto de la decadencia en la que se encontraba la Sindicatura Nacional de Quiebras ${ }^{97}$. Por último, nos encontramos ante la actual ley de quiebras, la cual, incluidas sus modificaciones posteriores, llevan adelante una visión privatista extrema, donde los acreedores se alzan con el máximo de facultades posibles ${ }^{98}$. Las juntas, entonces, hacen realidad el sueño subsidiario del Estado, entregando al fallido en manos de acreedores que pocas veces tienen la diligencia y técnica suficiente para hacer de la quiebra un pro-

95

Contreras Strauch, Osvaldo: Insolvencia y Quiebra, Ed. Jurídica de Chile, Santiago, 2010, p. 78

Eyzaguirre Smart, Gonzalo; Gómez Balmaceda, Rafael: El Derecho de Quiebras, T. II, Ed Jurídica de Chile, Santiago, 2011, p. 351.

Como dijimos, el conjunto de atribuciones otorgadas al ente público hizo que rápidamente hiciera agua ante tal cantidad de causas. Así, las potestades con las que contaba la Sindicatura, entre ellas las de fiscalizar las funciones de los síndicos, no pudieron ser cumplidas a cabalidad, pues nunca pudo un solo órgano llevar adelante facultades tan distintas y heterogéneas.

Contreras Strauch, Osvaldo: Instituciones de Derecho Comercial, T. II, Ed. Abeledo Perrot, Santiago, 2011, p. 1413. 
cedimiento de reorganización eficiente y acorde a las necesidades de un comercio cada vez más desarrollado.

La actual ley de quiebras, ha otorgado potestades supremas a los acreedores para la dirección del procedimiento, tanto en lo que respecta a su propia esfera de competencias ${ }^{99}$, como también en lo que respecta a su relación con otros órganos del procedimiento (léase síndico) ${ }^{100}$. En este contexto, la junta de acreedores se encuentra investida de las más amplias facultades, ya como sujeto procesal, como órgano deliberante y decisorio en la enajenación o liquidación del activo de la quiebra, o como órgano de fiscalización y de control de la actividad del síndico ${ }^{101}$.

El paso dado por nuestro legislador concursal es claro, y viendo sus fundamentos no podemos sino detectar la incorporación de potestades que nada tienen que ver con un sistema efectivo. En este contexto, y como bien dijimos, el legislador ha otorgado un sinfín de potestades a los acreedores, las que, sin embargo, no han sido ejercidas del modo que se esperaba. Así, salvo que se trate de pasivos concentrados en pocos acreedores, resulta tremendamente complicado siquiera lograr el quórum exigido por la ley para constituir la junta ${ }^{102}$. Incluso más, el procedimiento de mayor eficacia, hasta antes de la dictación de la ley No 18.175, era el contemplado en el Art. 84 de la ley No 4.558, el cual permitía tomar acuerdos fuera de la junta por escrito, y presentándolos luego al juzgado correspondiente. De esa forma, durante la tramitación de la actual ley de quiebras aún resultaba aventurado afirmar que todavía existiría la pasividad y resignación de los acreedores que tuvo en cuenta el legislador de 1928. Asimismo, también resultaba temerario afirmar que en la década de los 80 del siglo recién pasado, los acreedores en las quiebras sabrían hacer uso de las atribuciones que les entregaría el proyecto, el cual expropiaba ciertas facultades a los tribunales y síndicos, para hacer de la juntas el órgano supremo del proceso. Sin embargo, las propias actas legislativas nos indican que las interrogantes planteadas son totalmente inciertas, lo que ahondó en la preocupación por entablar un sistema subsidiario donde el destino de la quiebra quede principalmente en manos del síndico ${ }^{103}$.

La importancia de los comentarios anteriormente expuestos radica en la posibilidad que hoy tenemos, a casi 30 años de la publicación de la ley, de responder a dicha incertidumbre, la que no puede ser otra que la de reconocer un serio retroceso de nuestro sistema concursal. El gran

99 Dicha amplitud se manifiesta, además, en que las facultades otorgadas a las juntas ni siquiera son taxativas, pues el propio Art. 166 de la ley da la posibilidad de adoptar todos los acuerdos que estimen necesarios, proyectando el espectro de posibilidad de participación y dilación del procedimiento.

100 Para una revisión completa de sus poderes, Vid. Núñez OJEDA: (n. 8), pp. 223-242.

101 Torres Zagal, Oscar: Los Órganos de la Quiebra, Conosur, Santiago, 1993, p. 30.

102 Boletín No 174-05, p. 234.

103 Ibíd. 
número de facultades otorgadas a las juntas de acreedores en nuestra legislación han hecho de ella un engranaje bastante difícil de mover y poner en circulación, pues su propia estructura no permite dar al concurso la fisonomía propia de un sistema eficiente ${ }^{104}$. Es un hecho que los acreedores llegan muy interesados al procedimiento, aunque solo para conocer cuánto les corresponderá en definitiva, pero a medida que se van pagando los acreedores privilegiados y disminuye el patrimonio, los acreedores se desinteresan por la administración de la quiebra, aunque ella sigue adelante, llegando a un momento en el cual ni siquiera hay junta de acreedores, pues no hay quórum para su constitución. En esos casos, solo se encuentra el fallido y la Superintendencia para provocar que el procedimiento llegue a un fin ${ }^{105}$. Es así como a la dictación de la actual ley, existían quiebras pendientes de hace más de 20 años, lo que no correspondía necesariamente al atraso o lentitud de los síndicos, sino precisamente a lo difícil que resulta llevar a cabo un procedimiento donde los protagonistas no asisten. De ese modo, y a propósito de la objeción de las cuentas de los síndicos, la historia de la ley nos recuerda la importancia que se dio en su momento por dotar a la Fiscalía (hoy Superintendencia) de dicha facultad ya que, por un lado, obtienen información necesaria para el procedimiento, pero por el otro, muchas veces superaban la problemática de no encontrar una junta de acreedores que pudiese objetar dichas cuentas, por

104 Al respecto podemos traer a la luz al menos dos formas de evaluar la eficiencia de la quiebra en Chile: así, tal como nos comentan los profesores Bonilla y Gutiérrez, existe una tremenda relación entre las variables de recuperación y la duración del procedimiento. En Chile, el Banco Mundial estableció un tasa de recuperación solo del 23,12\%, lo que fue corregido por el estudio en cuestión a un 39\%, pues el órgano internacional solo se basó en encuestas hechas a los actores involucrados en el procedo de quiebra, por lo que solo respondería a percepciones. En todo caso, las cifras solo son demostrativas de la recuperación que puede alcanzar un acreedor privilegiado, pues en el caso de los valistas el estudio es categórico al señalar que prácticamente pierden el $100 \%$ de su crédito, por lo que si una empresa quiebra, sus proveedores pueden esperar no recibir nada en el proceso de liquidación, por lo que no tienen incentivos para participar del procedimiento, ni siquiera para intervenir en un convenio. Vid. Bonilla, Claudio; Gutiérrez, Elizabeth: "Los costos de Quiebras en Chile", en Estudios de información y control de gestión, Universidad de Chile, 2001, p. 41.

En segundo lugar, podemos apreciar otro punto importante para evaluar la eficiencia del sistema, cual es el tiempo que demora el mismo. Vimos que la tasa de recuperación es baja, pero ello se agrava al verificar que el tiempo promedio de una quiebra no responde a lo que el legislador estimó prudente en su oportunidad, lo que correspondía a un máximo de dos años. Así, otro interesante estudio nos demuestra que en un catastro de 32 empresas, el tiempo promedio que va desde la declaración de quiebra hasta la publicación de la última resolución, es de 40,7 meses, lo que se acerca mucho a lo que en las actas legislativas se consideró deficiente, lo cual fue de 48 meses. Vid. Bonilla, Claudio; Fischer, Ronald; LüDERs, Rolf; Mery, Rafael; TAgLe, José: "Análisis y recomendaciones para una Reforma a la Ley de Quiebras", Documentos de Trabajo del Centro de Economía Aplicada del Departamento de Ingeniería Industrial de la Universidad de Chile, 2004, N 191, p. 75. 
lo que si este órgano no lo hiciera, los síndicos en muchos casos podrían hacer lo que quisieran dentro de la quiebra ${ }^{106}$.

De este modo, el papel marcadamente protagónico que nuestro legislador otorga a las juntas, en desmedro de las potestades de los demás órganos de la quiebra, instituye a los primeros como los grandes directores y organizadores del proceso ${ }^{107}$. Ello ha generado un gran debilitamiento de la quiebra como un sistema efectivo de superación del estado de falencia del fallido, transformándolo en un proceso largo, lento y tedioso ${ }^{108}$.

Así, no resulta difícil intentar delinear un futuro más prometedor para el Derecho concursal a partir de la reestructuración de sus órganos. Es evidente que Chile necesita urgente un nuevo modelo concursal, donde la efectividad y eficiencia sea demostrada tanto en la regulación de sus órganos, como en el desenvolvimiento de estos dentro del procedimiento. En este contexto, hemos reseñado que existen al menos dos vías para subsanar los diversos problemas que trae aparejado el sistema de juntas: por un lado, rebajar sus poderes, y por otro, mantenerlos, pero estableciendo mecanismos que permitan mantener el principio de continuidad en el procedimiento (V. gr: Uruguay ${ }^{109}$ ).

Al tenor de todas las críticas comentadas al sistema imperante en nuestro país, es lógico que pretendamos subsanar dichas deficiencias con cambios más que cosméticos a nuestra legislación. Es así como resulta imperioso modificar sustancialmente nuestro sistema concursal, en vías de despojar a las juntas de acreedores de los poderes que lo han hecho sucumbir. No es menor que con dicha solución se radiquen ciertos costos económicos y de tiempo, presentes actualmente en nuestros concursos. De esa forma, se logran reducir fuertemente los gastos de convocatorias

106 Las ideas pertenecientes a las nuevas tendencias comentadas, no son totalmente ajenas a los trabajos doctrinales que han ido abriéndose paso en nuestro país. Es así, como podemos percatarnos que esa suerte de reorganización técnica de competencias, se ha planteado como idea reformista en nuestro sistema procesal de ejecución. Ello, porque la pretendida reforma procesal civil en la que se ha embarcado nuestro país, plantea la idea de "desjudicializar" el sistema (mas no "desjurisdiccionalizar"), donde la ejecución sea simplemente un trámite administrativo, llevado ante un funcionario denominado "oficial de ejecución", cuya naturaleza, facultades, prohibiciones y régimen disciplinario debiesen ser regulados por una ley especial que acompañe al nuevo proceso. De ese modo, el Art. 364 del mencionado proyecto, señala: "De la Ejecución Civil. La acción ejecutiva se ejercerá directamente ante el oficial de ejecución, sin necesidad de representación letrada ni de intervención del juez, sin perjuicio de las acciones que el ejecutado o terceros puedan impetrar con respecto a dicha ejecución, ante el juez de ejecución". Con ello, podemos demostrar que la eficiencia derivada de órganos técnicos y competentes (V. gr. administración concursal, oficial de ejecución), debiesen ser alternativas más que válidas para afrontar los aires reformistas que en nuestro medio se pretenden alcanzar. Vid, Núñez Ojeda, Raúl; Pérez Ragone, Álvaro; Meneses, Francisco: Diseño de un Modelo de Oficial de Ejecución, Subsecretaría de Justicia, Ministerio de Justicia, Chile, 2012.

107 Torres Zagal: (n. 104), p. 30.

108 Núñez Ojeda, Raúl: "Modernización de la Justicia concursal”, en Conferencia Colegio de Abogados de 13/10/2009, p. 5.

109 Vid, supra, p. 17. 
y notificaciones que comúnmente se suceden en el tiempo sin lograr la concurrencia necesaria para adoptar acuerdos que ni siquiera tienen que ver directamente con el futuro del procedimiento. En esa misma línea, rebajar las competencias de la junta significa inmediatamente reducir al mínimo la posibilidad de suspensión y paralización del procedimiento por falta de concurrencia, lo que significa disminuir drásticamente los tiempos de duración de la mayoría de los procedimientos que actualmente no encuentran salida ante la desidia de los acreedores. Fortalecer la economía del procedimiento y propender a la celeridad y continuidad del mismo son ventajas que ineludiblemente se han visto proyectadas en sistemas que adoptan dichas soluciones ${ }^{110}$.

Por otro lado, la importancia de rebajar los poderes de las juntas de acreedores no se limita a ello, sino muy por el contrario, se manifiesta fundamentalmente en la tendencia de redistribuir sus facultades en órganos técnicos y especializados que logren llevar efectivamente la marcha del procedimiento. De esta forma, no basta simplemente con disminuir el ámbito competencial de los acreedores reunidos en junta, sino que puede afirmarse que sirve mejor al interés de los mismos separar determinadas competencias y otorgárselas a otros órganos más preparados, jurídica y económicamente, para llevar el hilo conductor del concurso ${ }^{111}$.

Ha quedado demostrado que las juntas no son la mejor alternativa para aglutinar la mayor cantidad de competencias en el procedimiento concursal. La flexibilidad en su configuración como órgano colegiado, la amplitud no tasada de sus competencias y la dispersión y confusión de su régimen de funcionamiento ${ }^{112}$, han provocado que la junta sea desplazada, en esta idea de redistribución, solo al ámbito en que con mayor fuerza es necesaria: al debate y aprobación de los convenios en la forma en que en cada legislación se establece.

En el caso del juez, como segundo órgano del procedimiento concursal, también resulta evidente que no puede monopolizar todas las facultades que se pretenden extraer de la junta. Si bien es cierto, es posible que algunas facultades se radiquen absolutamente en él (V. gr: designación de síndico), dicho órgano no tiene una preparación adecuada para adoptar muchas de las decisiones que pueden platearse en el seno de un procedimiento concursal, como las de conveniencia netamente económica o la realización de determinadas inversiones que efectivamente exigen conocimientos especializados ${ }^{113}$. Asimismo, otorgar al juez las facultades que son propias de la junta, no soluciona en nada las dificultades comen-

110 Para un estudio acerca de dicha proyección en el derecho español, Vid, UlL SALCEDo, María Victoria: Los costes del nuevo procedimiento concursal, Dykinson, Madrid, 2006, passim.

111 Tirado: (n. 38), p. 304.

112 Quijano González: (n. 86), p. 66.

113 Tirado: (n. 38), p. 305. 
tadas a propósito del poder de decisión de los acreedores, pues con ello aumenta innecesariamente la burocracia del procedimiento, sacrificando infundadamente la celeridad y economía del mismo. Por otro lado, acrecentar dichas facultades, no solo provocaría un normal aumento de costos, sino también constituiría un pésimo paso hacia la añorada celeridad en nuestros tribunales civiles, los que están suficientemente cuestionados a propósito de la ejecución civil. Por lo demás, otorgar tal número de competencias al juez, haría necesario constituir delegados auxiliares del mismo para la realización de la mayoría de dichas diligencias ${ }^{114}$, desnaturalizando la redistribución técnica que se ha pretendido defender. Ello se erige como una crítica absolutamente insalvable en nuestro ordenamiento que, a diferencia del sistema español, carece de jueces mercantiles especializados ${ }^{115}$.

Por último, una fuente competencial tan grande asignada al juez ha provocado críticas desde el punto de vista del principio de imparcialidad, propio del ámbito jurisdiccional. En el sistema estadounidense, bajo la antigua ley de insolvencia, la BankruptcyCourt ejercía muchas de las funciones que hoy competen al U.S. Trustee, lo que fue profundamente criticado en el debate parlamentario de lo que hoy constituye el BankruptcyCode, pues las distintas facultades administrativas de la Corte se entrometían en su rol puramente jurisdiccional, lo que sumado a su íntima relación de supervisión con el Trustee, quien era un litigante regular en el caso, producía un compromiso de imparcialidad ${ }^{116}$.

De esta forma, llegamos al tercer órgano concursal, en quien se atribuye gran parte del poder decisional perteneciente a los acreedores. El síndico (o Administración Concursal en España) es el llamado a soportar gran cantidad de las facultades jurídicas y económicas propias del concurso, pues no sufre del desencanto y desidia propia de los acreedores y, a diferencia del juez, goza de total independencia e imparcialidad para el desempeño de sus funciones. Es por ello que, en prácticamente la totalidad de las legislaciones concursales, se ha exigido una gran profesionalización a dicho órgano, pues debe recoger gran parte de la tarea concursal asignada por la legislación de que se trate. En Chile, aun cuando sus funciones dependen, en gran parte, de la decisión de los acreedores, la ley de quiebras exige, además de un examen de conocimientos ante la Superinten-

\footnotetext{
114 Por dicha circunstancia han nacido ciertas reformas en los países con predominio de sistemas público como el francés, donde de a poco se ha ido empoderando a acreedores, mediante Comités, para subsanar defectos propios del sistema judicial.

115 Acerca del rol de juez en la reforma concursal española, Vid, González Granada, Piedad: Derecho Procesal Concursal, Coord. Guillermo Jiménez Sánchez, Ed. Marcial Pons, Madrid, 2008, pp. 42 y ss.; SeBASTián, Rafael: "Aproximación a la reforma del derecho concursal", en Actualidad Jurídica Uría \& Menéndez, No 6, 2003, pp. 21-33.

116 Blum, Brian A.: Bankruptcy and Debtor/Creditor, Little, Brown and Company, Boston, 1993, p. 158.
} 
dencia, tener el título de abogado, contador o ingeniero. En España, en donde la Administración Concursal goza de amplias facultades, la doctrina entiende a dicha institución como un ente basado, estructuralmente, en tres principios: la independencia, la formación profesional y la rapidez en su formación ${ }^{117}$. Así, bajo la reforma establecida por la Ley 38/2011, el nuevo artículo 27 de la ley concursal española exige al administrador tener al menos algunas de estas dos características: ser abogado en ejercicio con cinco años de experiencia y que hubiera acreditado formación especializada en Derecho Concursal, o ser economista, titulado mercantil o auditor de cuentas con cinco ańos de experiencia profesional, con especialización demostrable en el ámbito concursal ${ }^{118}$. Con ello, la legislación española ha pasado de un régimen de profesionalización impuro ${ }^{119}$ (donde el ente se componía por administradores profesionales, pero sin especialización en concursos) a uno totalmente puro, dando cuenta de la vital importancia que la Administración tiene en el concurso.

A partir de la profesionalización de este órgano, resulta totalmente factible adjudicarle gran parte del poder decisional en el concurso. Sus amplios conocimientos del Derecho Concursal hacen posible otorgarle la dirección jurídica del procedimiento y su basta experiencia en campo económico permiten atribuirle la posibilidad de verificación y evaluaciones de planes y propuestas de convenios ${ }^{120}$. De este modo, e incluso cuando la legislación española actual señala que la Administración concursal es compuesta, por regla general, por un solo miembro, la premisa recién señalada no pierde fuerza alguna, pues aun cuando el administrador sea abogado o economista, su especialización en materias concursales permiten que el procedimiento sea llevado a cabo con la máxima profesionalización posible.

Por ello, la legislación española avanza hacia el despojamiento de poderes de decisión de los acreedores, velando porque ellos sean ejercidos por un órgano técnico y especializado, el que desenvuelve sus funciones en todas las etapas del procedimiento concursal, las que han sido sistematizadas de la siguiente manera: fase común del concurso, fase de convenio, de liquidación, calificación del concurso y en su conclusión y reapertura $^{121}$.

Arribas Hernández, Alberto: Derecho Concursal, El Derecho Editores, Madrid, 2012, p. 111.

118 Campuzano, Ana Belén: Legislación Concursal, Coord. Carlos Nieto Delgado, Tirant lo Blanch, Valencia, 2012, p. 103.

Ramos ToRre: (n. 64), p. 341.

Para un examen específico de dichas etapas y las competencias de la Administración en cada una de ellas, Vid, Velázquez Martín, María Ángeles: Guía para una aproximación a la Administración concursal, Dykinson, Madrid, 2004, p. 35; López SÁnchez, Javier: El Proceso Concursal, Ed. Aranzadi, Navarra, 2012, pp. 487 y ss. 
En conclusión, resulta evidente que el debate no se centra en contraponer el poder de decisión de los acreedores con las facultades de los demás órganos de la quiebra, sino en dividir correctamente los ámbitos competenciales entre los sujetos privados (acreedores) y los llamados "órganos funcionales", definidos como aquellos creados legalmente con el mandato expreso de cumplir una función (juez y síndico) ${ }^{122}$. En este sentido, y teniendo en consideración la larga lista de críticas y elementos observados, el profesor Tirado ensaya una solución mediante un modelo interorgánico "correcto", que se basa fundamentalmente en proveer a los acreedores solo de las decisiones sustantivas de mayor importancia (V. gr: Convenio), radicar en la Administración concursal, la administración y los aspectos técnicos del procedimiento y en el órgano jurisdiccional las labores procesales y de control ${ }^{123}$.

La evolución legislativa nacional es clara en adoptar una solución ajena al modelo interorgánico descrito en el párrafo anterior. Las sucesivas reformas a la ley de quiebras no hacen más que acrecentar el ámbito competencial de los acreedores, aun cuando se han insertado normas para subsanar los defectos de dicho sistema ${ }^{124}$. No obstante, es evidente que dichas reformas no han significado un gran avance en la eficiencia del proceso concursal ${ }^{125}$, lo que ha derivado en diversos estudios a cargo de la Superintendencia de Quiebras ${ }^{126}$ para mejorar dicha problemática, arribando finalmente al actual proyecto de Ley enviado por el Poder Ejecutivo en el Mensaje $\mathrm{N}^{\circ}$ 081-360 y que ingresó al Congreso Nacional el 23 de mayo de 2012, el que contempla la nueva "Ley de Reorganización y Liquidación de empresas y personas". Esta iniciativa tiene el mérito de intentar erradicar muchas de las críticas aquí comentadas, estableciendo un procedimiento más ágil, fundamentado principalmente en el principio de conservación de la empresa ${ }^{127}$.

\footnotetext{
122 Tirado: (n. 38), p. 305.
}

123 Debemos dejar en claro que dicho modelo no es una descripción real del actual modelo español, sino simplemente corresponde a una visión ideal del autor, pues efectivamente aplica dicho modelo "correcto" para criticar algunos aspectos pendientes en la legislación española. Ibíd, p. 313. De esta forma, la crítica al modelo chileno no se basa en tentar una identificación con el sistema español, sino que busca la correspondencia con los principios expuestos en pos de buscar la solución más acorde al sistema concursal que se observe.

124 Núnez Ojeda, Raúl; Carrasco, Nicolás: Derecho Concursal Procesal Chileno, Abeledo Perrot, Santiago, Chile, 2011, pp. 446-449.

125 Según el último Informe Doing Business 2012, del Banco Mundial, Chile se encuentra en el lugar $\mathrm{N}^{\circ} 39$ en el ranking acerca de facilidad para emprender un negocio, lo que no ha variado demasiado de los anteriores informes, en donde se ubicaba en el lugar 41 (2011), pero, por otro lado, nuestro sistema concursal se ubica en el lugar 110 en materia de solución de insolvencias (En línea. En: www.doingbusiness.org; Consulta: 15 de marzo de 2012).

126 NúNEZ OJedA: (n. 8), passim.

127 A propósito de algunos méritos, se pretende rebajar los costos económicos que habíamos comentado a propósito de la falta de concurrencia de las juntas de acreedores, estableciendo 
En relación a las modificaciones orgánicas, se mantienen a los acreedores reunidos en junta y al juez como órganos necesarios de la quiebra, pero se elimina la figura del síndico para dar paso al llamado "Veedor" y al "Liquidador". El primero tiene como principal misión propiciar los acuerdos entre el deudor y sus acreedores, mientras que el segundo se encarga de realizar el activo del deudor y propender al pago de los créditos de sus acreedores (Art. $2^{\circ}$ del proyecto). Respecto al tema que hemos venido comentando, el proyecto tiene la gran virtud de reconocer expresamente la falta de interés que tienen los acreedores en los procedimientos concursales chilenos, empero, no adopta la solución que hemos planteado, sino que se encamina hacia la segunda solución propuesta: morigerar las deficiencias del sistema de juntas. Es así como el proyecto mantiene prácticamente incólume el gran volumen de competencias asignadas a los acreedores, pero establece expresamente ciertas soluciones para el caso de inasistencia de los mismos. Así, por ejemplo, el Art. 195, en relación con el Art. 203, seńala que ante la inasistencia de los acreedores en la segunda citación, el Liquidador titular provisional y suplente se entienden ratificados, y ante el alejamiento de los acreedores, pueden dar inicio al procedimiento de liquidación simplificada o sumaria. Por otro lado, el Art. 96 señala que el rechazo del acuerdo de Reorganización Judicial, por no haber contado con el quórum suficiente, provoca que el Tribunal pueda ordenar, de oficio y sin más trámite, la apertura del procedimiento concursal de liquidación.

Sin perjuicio de ello, una solución como la pretendida puede ser flanco de diversas críticas. Con abstracción de los ejemplos concretos que pueda otorgar el proyecto, y analizando dicha propuesta desde un punto de vista teórico, al menos podemos hacer dos precisiones. En primer lugar, las soluciones que se basan en resolver el problema de juntas, mediante la instalación de sanciones o presunciones de voluntad ante la falta de concurrencia de los acreedores, adolecen de un enorme esfuerzo casuístico. Intentar establecer vías de continuidad en el procedimiento, a partir de la ausencia de los acreedores, provoca que el legislador deba analizar caso por caso las consecuencias jurídicas de dicho abandono, no pudiendo abarcar, en la práctica, todas las decisiones que puedan adoptar los acreedores reunidos en junta. Por lo tanto, intentar llenar cada vacío que los acreedores dejen, conlleva al establecimiento de un sistema basado en excepciones ${ }^{128}$, y no en generalidades, donde prácticamente se desconoce a los acreedores como un sujeto interesado en el concurso, para dar paso

el llamado Boletín concursal, en el que se publican, por ejemplo, la circunstancia de falta de quórum a la junta que revisa la cuenta provisoria, de modo que los acreedores puedan acudir a la Superintendencia para revisarla en un momentos posterior.

Precisamente porque la regla general en nuestro sistema precisamente corresponde al ausentismo de los acreedores. Vid, Núñez OJeda; Carrasco: (n. 127), p. 446. 
simplemente a una interpretación legal de voluntades que nada tiene que ver con un sistema concursal comprensivo de los más amplios y diversos intereses.

En segundo lugar, una solución teórica como la recién planteada, pretende inclinar la balanza hacia la eficiencia, dejando de lado la eficacia. Nadie dudaría en lo veloz que pueda resultar una sentencia judicial dictada solo en un día; podríamos alabar un sistema procesal que se base en dicho principio de celeridad, pero conjuntamente podríamos dudar seriamente de la calidad de dicho resultado jurisdiccional. Aquí nos encontramos ante una solución parecida; no solo por la celeridad que se pretende inculcar al procedimiento concursal, sino también porque la vía elegida para ello, ante la desidia de los acreedores, es recurrir directamente a la liquidación sumaria de los bienes del deudor, dejando de lado otras vías que puedan ser, económicamente, mucho más rentables y efectivas para satisfacer los intereses, tanto del deudor como de los acreedores. Así, por ejemplo, una solución tan drástica inhibe la utilización de sistemas como la venta en unidad económica o la propia continuidad definitiva del giro, las que en caso de acreedores ausentes, prácticamente jamás se discutirían, contrariando flagrantemente el principio de conservación de la empresa, que se basa precisamente en la concurrencia de distintos intereses en la quiebra, la cual constituye una fuente de costos sociales y no solo una forma de transferencia de riquezas a los acreedores ${ }^{129}$.

En conclusión, es claro que ni la legislación actual ni la proyectada otorgan un panorama alentador acerca de la eficiencia y eficacia del procedimiento de quiebras, al menos desde el punto de vista de sus órganos. Desde una perspectiva funcional, hemos demostrado que estamos lejos aún de provocar la redistribución competencial que un sistema ideal pudiese tener.

\section{2.) Carácter Orgánico. Hacia una estructura representa- TIVA.}

Al igual que bajo la vigencia de la ley No 4.558, la Ley No 18.175 regula el funcionamiento y estructura de las juntas de acreedores. Ello se manifiesta a través del título VIII ("De las Juntas de Acreedores"), el cual comienza en el Art. 101 de la ley, que se encarga de estipular que los acreedores se reunirán en junta de acuerdo a las normas del título en comento. De ese modo, la ley de quiebras derogó totalmente las juntas de carácter obligatorio entabladas en su legislación antecesora por ser totalmente ineficaces, dando lugar a diversos tipos: la primera junta, también

129 Posner, Richard: El análisis económico del derecho,tr. de Eduardo Suárez, Fondo de Cultura Económica, 2008, p. 635. 
llamada constitutiva ${ }^{130}$, las ordinarias y las extraordinarias, suprimiendo los acuerdos realizados fuera de junta mediante presentaciones escritas al juzgado, las cuales habían sido de gran utilidad bajo la ley anterior, pues salvaban el defecto de no poder reunir los quórum necesarios para su constitución ni para llevar a cabo sus acuerdos.

La doble mayoría que impone nuestro sistema para el funcionamiento de la junta de acreedores, ha hecho que el procedimiento padezca de un profundo letargo ${ }^{131}$. Tan solo pensemos en que existen muchas ocasiones en que las juntas ni siquiera pueden constituirse por falta de quórum, lo que se agrava aún mas si recordamos los altos porcentajes de número y representatividad necesarios para adoptar los acuerdos en junta. Esta realidad ya ha sido objeto de diversas críticas en nuestra doctrina, pues se estima que "no parece desacertado confiar un rol activo a los acreedores en la Quiebra, pero tampoco resulta apropiado dejarles a ellos el manejo total de la administración y realización de los bienes, sobre todo si se piensa que tienen que actuar a través de la junta, que no es un órgano de funcionamiento permanente"132. En la misma línea, se ha señalado que "el nivel de atraso $y$ de estancamiento que tienen las quiebras se debe, esencialmente, a la falta de posibilidades y a la superposición de autorizaciones que se producen en Chile en base a sindicos, junta de acreedores, Superintendencia de Quiebras y jueces"133. Por último, Torres remata en su listado de críticas a los órganos de la quiebra, diciendo que las "juntas constituyen un órgano pesado, al cual hay que convocar legalmente, ocurriendo en la práctica que sean pocas las juntas que se realizan"134.

Así, desde un punto de vista netamente orgánico, la junta, como reunión de todos los titulares de créditos admitidos en el concurso, es un órgano inapropiado para la constante adopción de decisiones, pues sus necesarias normas de convocatoria y celebración convierten su funcionamiento en lento y costoso ${ }^{135}$.

De esta manera, los defectos que se han constatado en las juntas de acreedores, desde el punto de vista orgánico y funcional, pueden encontrar como solución una redistribución individual de las funciones

130 Esta primera reunión tiene trascendental importancia en el proceso de quiebras, ya que es en ella donde se fijan los aspectos principales respecto de la forma en que se desarrollará la misma. Viada Lozano, Alberto; Rojas Varas, Inés: Derecho de Quiebras, ConoSur, Santiago, 2001, p. 141.

131 Cfr. Bado, Virginia: "Mayorías en los procesos concursales", en Estudios Jurídicos, Publicación de la Facultad de Derecho de la Universidad Católica del Uruguay, No 3, 2007, p. 295, donde se da la idea de que, al menos teóricamente, las dobles mayorías cooperan en mantener la igualdad de los acreedores en la participación dentro del proceso. Sandoval López, Ricardo: "Los órganos de la Quiebra", en Revista de Derecho, Universidad de Concepción, V. LV, No 182, 1987, p. 97.

133 NúNEZZ OJEDA: (n. 111), p. 8.

134 TORRES ZAGAL: (n. 104), p. 100.

135 Tirado: (n. 38), p. 293. 
que se asignan a tal órgano. Así, por ejemplo, el legislador puede radicar determinadas decisiones derechamente en ciertos acreedores, bajo reglas de quórums, o bien, en algún otro órgano, representativo de los mismos intereses que la junta de acreedores, pero más técnico, económico, flexible y convocante que aquel (Comité o Comisión de acreedores).

La primera solución constituiría un paso hacia un extremo de lo que conocemos hoy. En efecto, atribuir directamente a los acreedores ciertas decisiones que actualmente poseen las juntas de acreedores, significaría establecer un régimen inorgánico de ejercicio de funciones de la masa activa. Con todo, cabe destacar que ello no resulta completamente ajeno a la técnica legislativa que conocemos en la normativa actual ${ }^{136}$ y proyecta$\mathrm{da}^{137}$, sin embargo, claramente constituye una excepción a la regla general, que asigna al órgano colectivo las decisiones más importantes.

En este sentido, desde la eficiencia, se podría consultar acerca de las razones por las cuales se contempla un órgano de la quiebra para el ejercicio de ciertas atribuciones, incluso cuando esas mismas facultades podrían recaer inmediatamente en los acreedores, sin necesidad de conformar algún cuerpo colectivo. La respuesta, que al parecer subyace a nuestra legislación, es que la reunión de acreedores podría reducir los costos de transacción tendientes a alcanzar ciertos acuerdos ${ }^{138}$. Sin embargo, ello solamente sería efectivo en el caso que las juntas de acreedores sean realmente convocantes, y la participación en ellas permita conocer las posiciones estratégicas de cada acreedor. Con todo, ambos supuestos no concurren.

La segunda solución, reflejada en la existencia de un comité o comisión de acreedores, nace con la pretensión de evitar que todos los acreedores deban participar activamente en cada una de las fases del procedimiento concursal, siendo la respuesta a una serie de problemas prácticos que han presentado los sistemas de juntas de acreedores como el

136 En este sentido, el artículo 30 inciso final del Libro IV del Código de Comercio, establece asignación de atribuciones a los acreedores para objetar cuenta definitiva del síndico. En este mismo sentido, los artículos 57, 60 inciso $3^{\circ}$, 61 inciso $2^{\circ}, 81,98$ y otras normas del Libro IV del Código de Comercio.

137 Por ejemplo, ello ocurre en el proyecto de ley contenido en el Mensaje $\mathrm{N}^{\circ}$ 081-360, con los artículos 22 inciso $2^{\circ}$ donde los tres mayores acreedores podrán proponer, en forma individual y sin actuar como órgano alguno, el nombre del veedor titular y suplente. En el mismo sentido, el artículo 49 se contempla la posibilidad de que los acreedores podrán formular sus observaciones a la cuenta provisoria publicada. En este caso, tales acreedores actúan al margen del funcionamiento de un órgano colectivo.

138 Los costos de transacción son todos los costos de información, de negociación y de monitoreo que supone la observancia de los derechos de propiedad y de los contratos. Dichos costos, obstaculizan el intercambio, y la cooperación mutuamente beneficiosa. Vid, Veljanovski, Cento; Economía del Derecho, tr. de Iñigo De la Maza y Rafael Mery, Ediciones Diego Portales, Santiago, 2006, p. 71. 
chileno $^{139}$. De este modo, incluso cuando se pretenda mantener incólume el ámbito competencial de los acreedores reunidos en junta, dicho sistema debiese avanzar hacia una estructura más ágil y representativa, manifestado precisamente mediante este tipo de comités.

En efecto, hemos visto con anterioridad que el desperfecto regulatorio fundamental de las juntas de acreedores lo constituye el hecho de que su citación, convocatoria y celebración van asociadas a costos importantes con cargo a la masa, así como también, resulta un vicio del sistema la escasa participación de los acreedores en ella.

Más allá de analizar las funciones y características de los comités en diversos ordenamientos, debemos señalar, primeramente, que existe un punto común importante, cual es la llamada "relación de agencia" existente en los acreedores (mandantes) y los miembros del comité (mandatarios) $)^{140}$. Sucede que la conformación que se pueda dar a un comité resulta enormemente importante para definir su futuro y éxito dentro de un sistema concursal, pues cuando los representantes (o mandatarios) deben velar por un interés que presenta una cierta uniformidad, resulta mucho más fácil operar con eficiencia y rapidez, mientras que cuando ese interés es diverso se dan los llamados "costos de agencia", en que no existe una completa correlación en lo perseguido por mandatarios y mandantes, pues los últimos representan círculos de interés completamente diversos entre sí, lo que deriva en posibles conflictos que se intentan manejar mediante diversas composiciones orgánicas, modos de nombramiento de los representantes o por medio de los distintos regímenes de retribución y responsabilidad.

Un ejemplo de lo anterior es la diferencia que existe entre los regímenes estadounidenses y alemanes. En los primeros, el creditors'committee está compuesto exclusivamente por acreedores elegidos de entre los titulares de créditos comunes, debiendo representar solo un tipo de interés, no importando si sus decisiones afectan a otros, como los acreedores no ordinarios o socios. En el segundo caso, el Gläubigerausschu $\beta$ de la ley de insolvencia vigente (Insolvenzordnung) compone al comité no solo con representantes de los pequeños acreedores ordinarios (Kleingläubiger), sino también con acreedores con derecho a satisfacción separada (absonderungberechtigtenGlaübiger), lo que obviamente provoca ciertos problemas prácticos a la hora de fraguar consensos ${ }^{141}$.

139 Áluarez San José: (n. 23), pp. 129 y ss.

140 Así, en el sistema estadounidense, la idea esencial detrás de los comités es la representación y salvaguarda de los intereses de los créditos que representan, no siendo solo un vigilante del deudor, sino también promover negociaciones que conduzcan a la formulación de plan de insolvencia. Vid, Blum: (n. 119), p. 158.

Para un análisis acerca de la estructura orgánica y funcional del Comité de acreedores alemán, Vid, Graf Brockdorff, Christian en Huntemann, Eva María; Graf Brockdorff, 
Lo anterior es sin perjuicio de que cada país contempla una regulación de los comités de acreedores de manera diversa, en cuanto a sus ámbitos de competencia, y composición. Se puede distinguir desde sistemas donde ejerce funciones consultivas y de supervisión (modelo italiano ${ }^{142}$ ); a otros, donde posee características de órgano negociador y decisorio (modelo norteamericano), o mixto (alemán).

Ahora bien, el comité de acreedores resulta un modelo de solución ajeno a la legislación nacional, a diferencia de lo que sucede con el establecimiento -a lo menos parcial- de un sistema de asignación de funciones a los acreedores, y que hemos visto existe en nuestro sistema actual y proyectado.

Solamente ha sido con el comentado proyecto de Ley enviado por el Poder Ejecutivo en el Mensaje $\mathrm{N}^{\circ}$ 081-360, que crea una nueva legislación concursal mediante la ley de reorganización y liquidación de empresas y personas, donde se contempla el establecimiento de un órgano de la quiebra denominado: "Comisión de acreedores".

Tal órgano se encuentra definido en el proyecto de ley en su artículo $2 \mathrm{~N}^{\circ}$ 9, como "aquella que se designa en un procedimiento concursal de reorganización con el objeto de supervigilar el cumplimiento del Acuerdo de Reorganización Judicial, con las atribuciones y deberes que el mismo señale, o aquella que se designa en un procedimiento concursal de liquidación, que tiene por objeto tomar los acuerdos que la junta de acreedores le delegue".

De esta forma, el proyecto de ley mencionado contempla el establecimiento de la comisión de acreedores en dos procedimientos, a propósito del procedimiento concursal de reorganización ${ }^{143}$, y a propósito del procedimiento concursal de liquidación.

Christian (Hrsg.): Der GläubigerimInsolvenzverfahren, Ed. De Gruyter, Berlin, 1999, pp. 292 y ss.

142 Acerca del Comitatodeicreditori, su nómina, funciones y poderes, Vid, PanZani, Luciano; Fauceglia, Giuseppe: Fallimento e altreprocedureconcorsuali, Ed. WoltersKluwer, Milano, 2009, pp. 343 y ss.; Ambrosini, Stefano; Cavalli, G.; Jorio, A.: IlFallimento, Ed. WoltersKluwer, Padova, 2009, pp. 286 y ss.; Bertacchini, Elisabetta Gualandi, Laura; Pacchi, Gaetano; Pacchi, Estefania; y Scarselli, Giuliano: Manuale di dirittofallimentare, Ed. Giuffré, Milano, 2011, p. 131.

143 Desde una perspectiva económica, la elección por la reorganización supone que los acreedores o interesados que opten por ella, lo hacen para capturar el mayor valor que pueden obtener en dicha alternativa, frente a lo que podrían llegar a recibir en un proceso de liquidación. Ello ocurrirá fundamentalmente cuando los acreedores generen mayor nivel de ganancia de la repartición de los beneficios que la empresa puede producir, en su calidad de accionistas o socios, que de su calidad de acreedores con un derecho de participación sobre el producto de realización del activo. Vid, BaIRD, Duglas G.: The Uneasy Case for Corporate Reorganizations, Journal Legal Studies, No 15, 1986, p. 127; Bевснuк, Lucian: A New Approach to Corporate Reorganizations, Harvard Law Review, V. 101, 1988, pp. 4-7; y Carrasco, Nicolás: Análisis Económico de las Medidas Cautelares Civiles, Abeledo Perrot, Santiago, 2011, pp. 297-310. 
En primer término, en lo que respecta al Acuerdo de Reorganización Judicial (en adelante, indistintamente "ARJ"), se trata de aquel que se suscribe entre una empresa deudora y sus acreedores, con el fin de reestructurar sus activos y pasivos, con sujeción al procedimiento de reorganización judicial que contempla el Título 1 y 2 del Capítulo III del proyecto de ley (Artículo $2 \mathrm{~N}^{\circ} 1$ del proyecto de Ley).

Ahora bien, la Comisión de Acreedores encuentra su regulación a propósito del ARJ en el artículo 70 del proyecto de ley. En tal norma, se contienen dos órganos de fiscalización de cumplimiento del acuerdo: (i) El interventor, que en esencia es el mismo que contempla el artículo 294 del Código de Procedimiento Civil, y que se consagra en el inciso primero, y (ii) La Comisión de Acreedores, que se regula en su inciso segundo, cuando señala que: "Sin perjuicio de lo anterior, en el Acuerdo de Reorganización Judicial se podrá designar a una Comisión de Acreedores para supervigilar el cumplimiento de sus estipulaciones, con las atribuciones, deberes y remuneración, en su caso, que el Acuerdo de Reorganización Judicial señale".

De la lectura de tal norma, podemos concluir que la Comisión de Acreedores en el contexto del Acuerdo de Reorganización Judicial, se configura como un órgano doblemente voluntario, toda vez que, en primer término, no podrá existir en aquellos casos en que el Acuerdo de Reorganización Judicial sea de ejecución inmediata, porque no existirá razón para su establecimiento, máxime si solamente ha sido contemplado para supervigilar el cumplimiento de las estipulaciones de tal acuerdo, lo que no se da en aquellos supuestos donde el momento de suscripción del acuerdo es coincidente con el de su ejecución o cumplimiento. En segundo término, su existencia depende de que en cada caso sea establecido en el ARJ. Dicho acuerdo determinará el ámbito de facultades de la Comisión, las que no vienen consagradas por la ley.

Desde la perspectiva de los costos de transacción involucrados, el proyecto de ley al no fijar sus competencias, integración u otras materias asociadas al funcionamiento de la Comisión de Acreedores, delega la negociación sobre dichos aspectos a los acreedores y al deudor. Tal técnica legislativa no resulta conveniente,, toda vez que, mientras mayor sea el número de aspectos a convenir en cualquier negociación, mayor es la probabilidad de divergencia entre los partícipes, aumentando ellas cuando se trata de regular aspectos relacionados a la fiscalización de un cumplimiento, ya que dicha labor se traduce en funciones de control de actos de otros $^{144}$. Por lo mismo, presumiendo actores racionales con miras a darle

144 La Comisión de las Naciones Unidas para el Derecho Mercantil Internacional (CNUDMIUNCITRAL), señala que cuando el legislador nacional permita el nombramiento de un comité de acreedores o de un representante de los mismos, se sugiere que debería especificarse claramente la relación entre ellos. Además, debe clarificar los acreedores elegibles (o inelegibles) para integrarlo, como también los mecanismos de nombramiento y los derechos 
viabilidad a un ARJ, y en presencia de tales divergencias, se optará simplemente por omitir el establecimiento de una Comisión de Acreedores.

Cabe agregar que dicha probabilidad aumenta, si es que el legislador otorga la posibilidad de establecer un segundo órgano de fiscalización (el interventor), con facultades definidas por ley, lo que se traduce en una alternativa más deseable desde la reducción de los costos involucrados ${ }^{145}$.

En otras palabras, frente a altos costos de transacción, la voluntariedad en la regulación de una determinada institución orgánica de fiscalización, puede traducirse en su no implementación.

En segundo término, la Comisión de Acreedores también se consagra en el proyecto de ley a propósito del procedimiento concursal de liquidación. Con todo, la situación orgánica de tal Comisión no varía de aquello analizado anteriormente respecto de su establecimiento en el ARJ.

En efecto, el Art. 202 del proyecto de ley, recalca el carácter voluntario y excepcional de la Comisión de Acreedores, al señalar que: "La Junta de Acreedores podrá acordar con Quórum Especial, la constitución de una Comisión de Acreedores, a efectos de adoptar con validez general los acuerdos que se comprendan dentro de la órbita de su competencia. Su composición, facultades, duración y procedimiento aplicables serán determinados por la propia Junta de Acreedores, con el mismo quórum anterior".

La normativa proyectada, en este caso, resulta incluso más paradójica. Lo anterior, debido a que el establecimiento de la Comisión de Acreedores requiere de un quórum especial, el que también se exigirá para determinar su composición, facultades, duración, y otros aspectos vinculados con su existencia. Sin embargo, dicho quórum especial basta para adoptar cualquiera de las facultades de la Junta de Acreedores, por lo tanto, no se entiende la necesidad de establecer otro órgano para alcanzar los mismos acuerdos que una Junta de Acreedores puede lograr. Se genera de esta forma una duplicidad orgánica, que no tiene mayor sentido.

Incluso más, resulta difícil entender que la Junta de Acreedores pueda delegar funciones en el Comité de Acreedores, porque no existe habilitación legal para ello. De forma que aquellas atribuciones y materias que compete resolver a una Junta de Acreedores (Arts. 196, 198 y 200 del proyecto de ley) nunca podrán ser objeto de decisión por parte del Comi-

y funciones de un comité. Vid, Morán Bovio, David: Guía legislativa de UNCITRAL sobre el régimen de la Insolvencia, Ed. La Ley, Madrid, 2007, pp. 145-146.

145 En efecto, las partes optarán por aquél sistema que reduzca los costos terciarios del sistema. Los costos terciarios son aquellos que se originan por la liquidación y distribución del daño producido. En el ámbito del Análisis Económico del Derecho, ellos se corresponden con los costos administrativos del sistema judicial, que se traducen en los gastos que se imponen a las partes, así como al Estado, para poder llevar a cabo la actividad judicial, y que se traduce en el precio del funcionamiento del proceso. Vid, Calabresi, Guido; El coste de los Accidentes: análisis económico y jurídico de la responsabilidad civil, tr. de Joaquín Bisbal, Editorial Arce, Barcelona, 1984, p. 349. Sobre litigación periférica, Vid, Posner: (n. 132), p. 629. 
té de Acreedores, en circunstancia, que las materias señaladas en dichos artículos, constituyen los aspectos de mayor relevancia en el funcionamiento de un órgano colegiado de acreedores. Por lo mismo, el ámbito de decisión del Comité de Acreedores, para el caso que se cree, abarcará aspectos secundarios. Ello hace más difícil su establecimiento, porque se reinstala el mismo problema actual, en cuanto a que si no existe interés en participar en las juntas de acreedores en aquellas materias importantes, menos interés existirá en acordar, con un quórum alto, el surgimiento de un órgano para discutir temas de menor relevancia.

Por último, el proyecto de ley contenido en el Mensaje $N^{\circ} 081-360$ no contiene una opción legislativa tendiente a consagrar un sistema orgánico que se haga cargo de las deficiencias de las Juntas de Acreedores. Ello ocurre debido a que no establece como regla general un sistema de atribución directa de facultades a los acreedores, ni tampoco por consagrar un órgano más flexible, económico y convocante que la Junta de Acreedores, como lo es, en la experiencia comparada, el Comité o Comisión de Acreedores. Esto último, debido a que la regulación a su respecto, importa delegar su establecimiento en los acreedores, bajo altos costos de transacción, e intereses divergentes.

\section{CONCLUSIÓN}

Ha quedado claro que el paso dado por nuestro legislador (actual y proyectado) ha dado pie a un sistema de corte total y absolutamente privatista, lo que ha sido abandonado en las nuevas tendencias comparadas. El derecho actual ha implantado sistemas que, si bien son privados, se caracterizan por ser mucho más inorgánicos que los nuestros, dándonos a entender que un órgano tan pesado como la junta, no es ni puede ser la salida única y exclusiva para poder afrontar la insolvencia dentro de una sociedad. Por otro lado, la visión funcional nos ha ayudado para reconocer que las juntas no necesariamente deben llevar el protagonismo del proceso, sino que puede darse pie a otras alternativas, provocando una reducción funcional a favor de órganos más técnicos y competentes para llevar a cabo dichos poderes.

Es así como se requiere una pronta reestructuración técnica y profesional de nuestros órganos concursales, de modo de redistribuir las facultades según el grado de especialización de cada participe. Además, $y$ aun cuando pensemos en mantener a los acreedores reunidos en junta como los directores del procedimiento, es necesario avanzar hacia una estructura representativa, de modo de incentivar su participación mediante órganos más ágiles y menos pesados, integrados precisamente en base a criterios de eficiencia y eficacia, tratando de proyectar dichos adjetivos, no 
solo a las características fundamentales de los intervinientes en el proceso, sino también a todas las etapas del mismo.

\section{Bibliografía}

- Álvarez San José, María: El poder de decisión de los acreedores en el concurso, Ed. Civitas, Madrid, 2005.

- Ambrosini, Stefano; Cavalli, G.; Jorio, A.: IlFallimento, Ed. WoltersKluwer, Padova, 2009.

- Arriagada, Juan Pablo: "Pervivencia de Principios e Instituciones romanas en la Quiebra chilena", Memoria para optar al grado de licenciado en ciencias jurídicas, Santiago, 1996.

- Arribas Hernández, Alberto: Derecho Concursal, El Derecho Editores, Madrid, 2012.

- BAdo, Virginia: "Mayorías en los procesos concursales", en Estudios Jurídicos, Publicación de la Facultad de Derecho de la Universidad Católica del Uruguay, No 3, 2007.

- Baeza Ovalle, José Gonzalo: Derecho concursal: procedimiento de liquidación de bienes. La Quiebra, Vol. III, PuntoLex, Santiago, 2011.

- Baird, Duglas G.: The Uneasy Case for Corporate Reorganizations,Journal Legal Studies, No 15, 1986.

- Barrio Calle, María Asunción, La Administración Concursal (en línea). En: www.cej-mjusticia.es, [consulta: 01 de Octubre de 2011].

- Bebchuk, Lucian: A New Approach to Corporate Reorganizations,Harvard Law Review, Vol. 101, 1988.

- Bertacchini, Elisabetta; Gualandi, Laura; Pacchi, Gaetano; Pacchi, Estefania; y Scarselli, Giuliano: Manuale di dirittofallimentare, Ed. Giuffré, Milano, 2011.

- Betancourt, Fernando: "El concurso de acreedores en el Derecho Romano clásico", en Estudios sobre la Ley concursal: libro homenaje a Manuel Olivencia, Marcial Pons, Madrid, 2005.

- Blum, Brian A.: Bankruptcy and Debtor/Creditor, Little, Brown and Company, Boston, 1993.

- Böнm, Bastian: "Die Gläubiger - Gläubigergruppen, Gläubigerorganisation, Gläubigerversammlung”, en Handbuch des Insolvenzrechts, Editor Karl WolfhartNitsch, Ed. EHV, Bremen, 2011.

- Bonilla, Claudio; Fischer, Ronald; Lüders, Rolf; Mery, Rafael; TAgle, José: "Análisis y recomendaciones para una Reforma a la Ley de Quiebras", Documentos de Trabajo del Centro de Economía Aplicada del Departamento de Ingeniería Industrial de la Universidad de Chile, 2004, Nº 191. 
- Bonilla, Claudio; Gutiérrez, Elizabeth: "Los costos de Quiebras en Chile", en Estudios de información y control de gestión, Universidad de Chile, 2001.

- Calabresi, Guido: El coste de los Accidentes: análisis económico y jurídico de la responsabilidad civil, trad. Joaquín Bisbal, Editorial Ariel, Barcelona, 1984.

- Calvo Caravaca, Alfonso Luis y Carrascosa González, Javier: Derecho concursal internacional, Colex, Madrid, 2004.

- Campuzano, Ana Belén: Legislación Concursal, Coord. Carlos Nieto Delgado, Tirant lo Blanch, Valencia, 2012.

- Carrasco, Jorge: Evolución del Derecho de Quiebras en Chile, Ed. Jurídica, Santiago, 1963.

- Carrasco, Nicolás, Análisis Económico de las Medidas Cautelares Civiles, AbeledoPerrot, Santiago, 2011.

- Cifuentes Corona, Pablo: Los convenios judiciales, estudio de las alternativas a la quiebra, Copygraph, Santiago, 2009.

- Contreras Strauch, Osvaldo: Insolvencia y Quiebra, Ed. Jurídica de Chile, Santiago, 2010.

- Contreras Strauch, Osvaldo: Instituciones de Derecho Comercial, T. II, Ed. AbeledoPerrot, Santiago, 2011.

- Dasso, Ariel: Derecho Concursal Comparado, T. I y II, Legis, Buenos Aires, 2007.

- Depré, Peter; Eickmann, Dieter, Flessner, Alex, VV.AA, Insolvenzordnung. Heidelberg Kommentar, (Hrsg.Gerhard Kreft), CF. Müller, Heidelberg, 2008.

- Desurvire, Daniel: "La Quiebra a través de los tiempos", en Revista de Derecho, Universidad de Concepción, V. LXIV, No 199, 1996.

- Eyzaguirre Smart, Gonzalo; Gómez Balmaceda, Rafael: El Derecho de Quiebras, T. II, Ed. Jurídica de Chile, Santiago, 2011.

- Fernández Torres, Isabel: "La representación de los acreedores por la Administración Concursal: Una prohibición implícita", en Anuario de Derecho Concursal, No 10, 2007.

- Ferriell, Jeff; Janger, Edward: Understanding Bankruptcy, Segunda ed., Ed. LexisNexis, New York, 2007.

- Forster, Wolfgang: KonkursalsVerfahren: Francisco Salgado de Somoza in der Geschichte des Insolvenzrechts, Ed. Böhlau, Köln, 2008.

- Gadea, Enrique: Iniciación al estudio del derecho concursal, Ed. Dykinson, Madrid, 2005.

- Garrigues, Joaquín: Curso de Derecho Mercantil, T. V., Temis, Bogotá, Colombia, 1987.

- Gómez Martín, Fernando: "La Administración Concursal”,en Estudios de Deusto, V. 2, No 50, 2002. 
- González Granada, Piedad: Derecho Procesal Concursal, Coord. Guillermo Jiménez Sánchez, Ed. Marcial Pons, Madrid, 2008.

- Hess, Harald: Insolvenzrecht, Ed. Müller, Heidelberg, 2007.

- Hess, Harald: Insolvenzrecht: Großkommentar in dreiBänden, V. 1, Ed. Müller, Heidelberg, 2007.

- Huntemann, Eva María; Graf Brockdorff, Christian (Hrsg.): Der GläubigerimInsolvenzverfahren, De Gruyter, Berlin, 1999.

- Laborderie, Pierre: "La Masa de acreedores y el control de la quiebra", en Revista de Derecho y Jurisprudencia y Gaceta de Tribunales, V. 1, No 15, 1918.

- Lo Cascio, Giovanni: IlFallimento, Ed. Klüwer, Italia, 2007.

- López SÁnchez, Javier: El Proceso Concursal, Ed. Aranzadi, Navarra, 2012.

- Morán Bovio, David: Guía legislativa de UNCITRAL sobre el régimen de la Insolvencia, Ed. La Ley, Madrid, 2007.

- Newton, Grant: Bankruptcy and Insolvency Accounting, Practice and Procedure, $7^{\circ}$ ed., Ed. John Wiley\&Sons, UnitesStates of America, 2009.

- Núñez Ojeda, Raúl; Carrasco, Nicolás: Derecho Concursal Procesal Chileno, Abeledo-Perrot, Santiago, Chile, 2011.

- Núñez Ojeda, Raúl, Estudio sobre Justicia Concursal para la Superintendencia de Quiebras, Cuarto Informe, Superintendencia de Quiebras, Santiago de Chile, 2009.

- Núñez OJedA, Raúl: "Modernización de la Justicia concursal", en Conferencia Colegio de Abogados de 13/10/2009.

- Núñez Ojeda, Raúl; Pérez Ragone, Álvaro; Meneses, Francisco: Diseño de un Modelo de Oficial de Ejecución, Subsecretaría de Justicia, Ministerio de Justicia, Chile, 2012.

- Pacheco Guevara, Andrés: La administración concursal, Aranzadi, Navarra, 2009.

- Pannen, Klaus: European Insolvency Regulation: Commentary, Ed. De Gruyter, Berlin, 2007.

- Panzani, Luciano; Fauceglia, Giuseppe: Fallimento $e$ altreprocedureconcorsuali, Ed. WoltersKluwer, Milano, 2009.

- Pérez Ragone, Álvaro; Silva, Oscar: "Deber de transparencia patrimonial y efectividad de la ejecución: corolario del imperativo de cooperación procesal”, en Cuadernos de Extensión Jurídica, U. De Los Andes, No 16, 2009.

- PetitLavall, María Victoria: "La Junta de Acreedores", en Estudios sobre la Ley concursal: libro homenaje a Manuel Olivencia, Marcial Pons, Madrid, 2005.

- Posner, Richard: El análisis económico del derecho, tr. de Eduardo Suárez, fondo de Cultura económica, 2008. 
- Provinciali, Renzo: Tratado de Derecho de Quiebra, T. III, Barcelona, 1959.

- Puga VIal, Juan: Derecho Concursal. El juicio de Quiebras, T. II, Tercera ed., Ed. Jurídica, Santiago, 2009.

- Pulgar Ezquerra, Juana: La Declaración del Concurso de Acreedores, Ed. La Ley, Madrid, 2005.

- Quijano González, Jesús: "La junta de acreedores en el nuevo derecho concursal", en Estudios sobre la Ley concursal: libro homenaje a Manuel Olivencia, Marcial Pons, Madrid, 2005.

- Quijano González, Jesús: "La Junta de Acreedores en la nueva legislación concursal", en Revista de derecho concursal y paraconcursal: Anales de doctrina, praxis, jurisprudencia y legislación, № 3, Madrid, 2005.

- Ramos Torre, Javier: "La Administración concursal", en Cuadernos de Derecho judicial, No 18, 2003.

- Reischl, Klaus: Insolvenzrecht, Ed. Müller, Heidelberg, 2008.

- Rivera, Julio; Roitman, Horacio; Vítolo, Daniel: Ley de Concursos y Quiebras, T. III, Ed, Rubinzal-Culzoni, Buenos Aires, 2000.

- Rojo, Ángel; Beltrán, Emilio: Comentario de la ley concursal, T. I y II, Ed. Civitas, Madrid, 2004.

- Román Rodríguez, Juan Pablo: Instituciones de Derecho Concursal, Abeledo Perrot, Santiago, 2011.

- Salas González, Manuel: "De las Quiebras: (comentarios sobre algunas disposiciones sustantivas del titulo IV de la ley 4.558)", Memoria de prueba para optar al grado de licenciado en ciencias jurídicas, Santiago, 1940.

- Sánchez-Calero Guilarte, Juan; Adrián Arnaiz, Antonio Javier: Comentarios a la legislación concursal, V. I, Ed. Lex Nova, Valladolid, 2004.

- Sandoval López, Ricardo: Derecho Comercial, La insolvencia de la empresa. Derecho Concursal: Quiebras, convenios y cesiones de bienes, Sexta ed, Ed. Jurídica, Santiago, 2007.

- Sandoval López, Ricardo: "Los órganos de la Quiebra”, en Revista de Derecho, Universidad de Concepción, V. LV, No 182, 1987.

- Sebastián, Rafael: "Aproximación a la reforma del derecho concursal”, en Actualidad Jurídica Uría \& Menéndez, No 6, 2003.

- SozaRied, María de los Ángeles: "El procedimiento concursal del derecho romano clásico y algunas de sus repercusiones en el actual derecho de quiebras", en Revista de estudios histórico-jurídicos, Valparaíso, No 20, 1998.

- Tirado, Ignacio: Los Administradores Concursales, Ed. Thomson Civitas, Navarra, 2005. 
- Torres Zagal, Óscar: Los Órganos de la Quiebra, ConoSur, Santiago, 1993.

- Ull Salcedo, María Victoria: Los costes del nuevo procedimiento concursal, Dykinson, Madrid, 2006.

- UnitedNations: Guia Legislativa sobre el Régimen de la Insolvencia, UnitedNationsPublications, 2006.

- Vacas Medina, Luis: "Críticas a los procesos concursales vigentes", Ponencia presentada en las "Jornadas de Derecho Procesal", enero, Madrid, 1984 (en línea). En www.mjusticia.gob.es [consulta: 10 de julio de 2012].

- VÁzquez Sotelo, José Luis: "La Nueva ley concursal española”, en Revista Iberoamericana de Derecho Procesal, V. IV, No 6, 2004.

- Velázquez Martín, María Ángeles: Guía para una aproximación a la Administración concursal, Dykinson, Madrid, 2004.

- Veljanovski, Cento: Economía del Derecho, tr. de Ińigo de la Maza y Rafael Mery, Ediciones Diego Portales, Santiago, 2006.

- Viada Lozano, Alberto; Rojas Varas, Inés: Derecho de Quiebras, ConoSur, Santiago, 2001.

- Yanes Yanes, Pedro: "La reforma inacabada de la administración concursal en el real decreto-ley 3/2009, de 27 de marzo", en Revista de derecho concursal y paraconcursal: anales de doctrina, praxis, jurisprudencia y legislación, No 11, Madrid, 2009. 